\title{
Hexyl alginate derivative, an amphiphilic innovative buccal film-forming material of promising mechanical and release characteristics for the improvement of repaglinide bioavailability
}

This article was published in the following Dove Medical Press journal:

Drug Design, Development and Therapy

\author{
Ahmed Khames ${ }^{1,2}$ \\ 'Department of Pharmaceutics \\ and Industrial Pharmacy, Faculty \\ of Pharmacy, Beni-Suef University, \\ Beni-Suef 625।4, Egypt; ${ }^{2}$ Department \\ of Pharmaceutics and Industrial \\ Pharmacy, College of Pharmacy, \\ Taif University, Taif 21974, Saudi Arabia
}

Background: Association of long hydrocarbon chain with alginate molecule imparts surface active properties and increases chain flexibility.

Purpose: This work studied the efficacy of synthesized hexyl alginate derivative as a filmforming material with unique amphiphilic and mechanical properties for the preparation of rapidly disintegrating repaglinide oral films with higher drug release rate and improved bioavailability. Methods: Alginate hexyl amide derivative was prepared and used in the formulation of oral films by solvent casting technique. Using Box-Behnken experimental design, formulations were optimized at different polymer, plasticizer, and disintegrant levels as independent variables for maximum drug release rate, higher tensile strength, and shortest disintegration time as responses. Optimized film formulae were fully evaluated and subjected to further in vivo bioavailability studies in rabbits.

Results: Higher dependency of response results on the selected variables was observed. Optimized formula showed satisfactory tensile strength $\left(145.862 \mathrm{~g} / \mathrm{cm}^{2}\right)$, rapid disintegration (22.2 seconds), and higher drug release rate (97.799\% within 30 minutes). The drug bioavailability was significantly improved in comparison with plain drug and conventional alginate oral films, where the AUC and $\mathrm{C}_{\text {max }}$ values reached $296.072 \mu \mathrm{g} . \mathrm{h} / \mathrm{mL}$ and $116.932 \mu \mathrm{g} / \mathrm{mL}$ in comparison with $164.917 \mu \mathrm{g} . \mathrm{h} / \mathrm{mL}$ and $56.568 \mu \mathrm{g} / \mathrm{mL}$ for alginate film and $95.368 \mu \mathrm{g} . \mathrm{h} / \mathrm{mL}$ and $31.925 \mu \mathrm{g} / \mathrm{mL}$ for plain drug, respectively. $\mathrm{T}_{\max }$ also showed significant reduction to be only 30 minutes in comparison with 60 minutes for other forms.

Conclusion: This led to the final conclusion that the synthesized alginate derivative is an innovative promising film-forming material with unique mechanical and drug release properties for application in buccal drug delivery especially of Biopharmaceutics Classification System (BCS) class II drugs to increase solubility and improve bioavailability.

Keywords: amphiphilic derivatives of alginate, Box-Behnken, BCS class II drugs, oral films, repaglinide

\section{Introduction}

Revolution in the field of polymer chemistry played a significant role in the production of new biopolymers and macromolecular complexes of great importance in the pharmaceutical/biomedical area including drug delivery systems, ${ }^{1,2}$ and recently, modification, design, and synthesis of new biomedical polymers as carriers for drug delivery with tissue targeting ${ }^{3-5}$ and/or drug release control ${ }^{6-8}$ characteristics represent a promising research interest in the pharmaceutical field, especially biocompatible and
Correspondence: Ahmed Khames Faculty of Pharmacy, Beni-Suef University, Salah Salem Str, Beni-Suef 625I4, Egypt

Tel +20 I22 7706985

Email dr_akhames@yahoo.com 
biodegradable polymers that are easily eliminated by normal metabolic pathways into safe byproducts. ${ }^{9-11}$

Polysaccharides are biodegradable, swellable, mucoadhesive, and physiologically compatible. In addition, they are liable to different chemical and enzymatic reactions. ${ }^{12-15}$ This strongly supports their use as precursors for chemical modification and production of new derivatives of versatile pharmaceutical applications. ${ }^{16,17}$ Polysaccharides of marine origin especially from seaweeds (alginate, agar, and carrageenan) show expandable potential application in pharmaceutical field due to flexibility of the production process, easy control on product yield, and rapid progression of in vitro production techniques, which also encouraged the discovery of new polysaccharides and development of many chemical and physical derivatives of interesting properties. ${ }^{18,19}$

Alginate is a polymeric molecule composed of 1,4-linked $\alpha$-L-guluronic ( $\mathrm{G}$ ) and $\beta$-D-mannuronic (M) residues irregularly arranged in block-wise manner along the linear polysaccharide chain derived mainly from cell wall of brown seaweed algae. It has many pharmaceutical applications due to its unique properties in comparison with other polysaccharides and carbohydrates. ${ }^{20,21}$ Presence of hydroxyl and carboxylic function groups within the alginate molecule attracted many chemists and polymer designers to pay more attention to the chemical modification on the polymer backbone through substitution of a hydrophobic long alkyl chain on the partially esterified carboxylic groups for the synthesis of many amphiphilic alginate derivatives of significant pharmaceutical values especially in drug delivery. ${ }^{22}$

Although the conventional oral route is the most popular drug administration route, ${ }^{23}$ it suffers many drawbacks mainly due to the interaction with gastrointestinal tract content and first pass metabolism of liable drugs that significantly affects their bioavailability. ${ }^{24}$ Patients with difficulty in swallowing, unconscious, and non-cooperatives add more complexity to these drawbacks. ${ }^{25,26}$ The buccal cavity is considered an optimum substituent route for drug administration which bypasses hepatic degradation and allows faster drug absorption due to high vascularity, relatively thin membrane, low degree of keratinization, and higher drug permeability of the lining mucosa. ${ }^{27}$

Fast dissolving film is a new drug delivery system that mainly uses a hydrophilic polymer as drug carrier, when located on the tongue, it instantly disintegrates/dissolves in saliva. It is a simple, convenient, and rapid means of buccal administration without any fear of accidental chewing and swallowing. ${ }^{28}$

Repaglinide (REP), meglitinide phenylalanine analog, is an oral short-acting antidiabetic drug used for type II diabetes patients. REP acts by selective blockage of ATP-dependent
$\mathrm{K}$ channel cellular membrane in pancreatic beta cells with subsequent stimulation of insulin secretion. It is extensively metabolized by hepatic cytochromes into inactive metabolites with poor bioavailability $(60 \%)$. It is a BCS class II drug, where dissolution is the absorption rate determining step with significant effect on drug bioavailability. ${ }^{29}$

In a previous study, ${ }^{30}$ amphiphilic alginate hexyl amide derivative (AHAD) was synthesized and its surface active properties were indicated, also its positive effect on drug release was studied. In this work, the efficacy of the synthesized alginate derivative as an innovative film-forming material with unique amphiphilic and mechanical properties for the preparation of rapidly disintegrating oral film was investigated using REP as a drug model.

\section{Materials and methods Materials}

REP (kindly supplied from EIPICO, 10th Ramadan City, Egypt), AHAD (synthesized according to the published work), N,N'-diisopropylcarbodiimide (DIC; Fluka, Switzerland), sodium alginate (Hipure, Genzyme, England), diazepam, starch sodium glycolate (SSG), hexyl amine, and aspartame (Sigma-Aldrich Co., St Louis, MO, USA). All other solvents are HPLC grade (Sigma-Aldrich Co.), animals: albino male rabbits (purchased from animal house of Taif University, Taif, KSA).

\section{Methodology}

\section{Synthesis of AHAD}

AHAD of alginate was prepared according to the method applied by Khames et al. ${ }^{30}$ Briefly, DIC ( $4.41 \mathrm{~g}, 0.035 \mathrm{M}$ ) was added to an aqueous sodium alginate solution $(10.40 \mathrm{~g} / 500 \mathrm{~mL}$, $0.05 \mathrm{M})$ after neutralization with nitric acid $(1.5 \mathrm{M}, 100 \mathrm{~mL})$ while stirring. After 2 hours, hexyl amine $(7.07 \mathrm{~g}, 0.07 \mathrm{M})$ was added, and the $\mathrm{pH}$ was raised to 6 by using sodium hydroxide solution $(2.0 \mathrm{M})$ and left for 2 hours. The $\mathrm{pH}$ was further raised to 9 and left overnight. Finally, nitric acid $(100 \mathrm{~mL}$, $1.5 \mathrm{M})$ and acetone $(1,000 \mathrm{~mL})$ were added to terminate the reaction by precipitation. The precipitate was filtered and thoroughly washed with suitable volume of acetone and ethanol. The resulting white AHAD polymer was dried in a desiccator.

\section{Preparation of REP-AHAD oral films}

REP oral films were prepared by solvent casting technique. For that, AHAD polymer was finely grounded and sieved through 40 mesh screen to remove any large, hard particles that may retard polymer dissolution during preparation. REP $(10 \mathrm{mg}$ ) was dispersed in $50 \mathrm{~mL}$ distilled water containing 
plasticizer (glycerol) in the specified amount. Weighed amount of AHAD polymer was added, and the mixture was slowly stirred at $60^{\circ} \mathrm{C}$ on water bath until complete dissolution of the polymer. Away from water bath, SSG (as disintegrant) and aspartame (as sweetener) were added and the stirring was continued for further 5 minutes. The solution was slowly and continuously casted onto glass plates of diameter $6 \mathrm{~cm}$ and dried in oven at $40^{\circ} \mathrm{C}$ for 24 hours. Films were removed from the plates, cut into $2 \times 2 \mathrm{~cm}$ dimension strips and stored in desiccator until further evaluation.

\section{Experimental design}

For the optimization of the prepared REP-AHAD oral films, three level, three factor Box-Behnken statistical design (Design Expert, Version 8.0.3, Stat-Ease Inc., Minneapolis, $\mathrm{MN}$, USA) was applied to evaluate the main, interaction, and quadratic effects of AHAD concentration (A), plasticizer concentration (B), and disintegrant concentration (C) as independent variables at three different levels on the characteristics of the prepared formulae including cumulative drug release $\left(R_{1}\right)$, tensile strength $\left(R_{2}\right)$, and disintegration time $\left(R_{3}\right)$ as dependent variables (responses).

The independent variables with their low, medium, and high levels together with the responses are presented in Table 1. Experimental design matrix of 17 runs (REP-AHAD oral film formulae) including five center points was constructed.

\section{Optimization and data analysis}

According to the experimental design matrix, the collected response values were fitted to linear, linear two-factor interaction (2FI), quadratic, and also cubic models, and mathematical polynomial equations were derived. The appropriate, highly fitted model was suggested based on higher determination coefficients and significance value at determined probability level. ANOVA (available in the software) was

Table I Formulation variables and their levels in Box-Behnken design

\begin{tabular}{l|l|l|l}
\hline \multirow{2}{*}{ Factor } & \multicolumn{2}{l}{ Level } \\
\cline { 2 - 4 } & $-\mathbf{I}$ & $\mathbf{0}$ & $\mathrm{I}$ \\
\hline Independent variables & & & \\
$\mathrm{A}:$ AHAD concentration $(\% \mathrm{w} / \mathrm{w})$ & $\mathrm{I}$ & 2 & 3 \\
$\mathrm{~B}:$ Plasticizer concentration $(\% \mathrm{w} / \mathrm{w})$ & 10 & 20 & 30 \\
$\mathrm{C}:$ Disintegrant concentration $(\% \mathrm{w} / \mathrm{w})$ & 5 & 10 & 15 \\
\hline Dependent variables & Constraint & \\
$\mathrm{R}_{1}:$ Cumulative drug release rate $(\% \mathrm{w} / \mathrm{v})$ & Maximize \\
$\mathrm{R}_{2}:$ Tensile strength $\left(g / \mathrm{cm}^{2}\right)$ & Maximize \\
$\mathrm{R}_{3}:$ Disintegration time $($ seconds) & Minimize \\
\hline
\end{tabular}

Abbreviation: AHAD, alginate hexyl amide derivative. applied to statistically validate the derived polynomial model equations, and three dimensional (3D) graphs and perturbation plots were also generated and studied.

\section{Validation of the method and derived equations}

To assess and validate the capability of the derived polynomial equations and plots for accurate prediction of the collected responses, checkpoint analysis was performed. For that, five optimized formulations were randomly selected depending on the calculated desirability factor. The checkpoints (optimized formulae) were formulated according to the proposed optimal composition and evaluated for the selected responses (observed). The observed response values were compared to the predicted values, prediction errors (\%) were calculated, and correlation plots were also constructed and compared.

\section{Evaluation of the prepared REP-AHAD films \\ Determination of tensile strength}

The tensile strength of the prepared oral films was measured using Brookfield CT-3 Texture Analyzer equipped by TA-DGA fixture probe (CT3-10,000 load cell model; Brookfield Engineering Lab. Inc., Middleboro, MA, USA). For measurement, the tested film sample $(2 \times 2 \mathrm{~cm})$ was positioned between the two clamps of the probe separated by $2 \mathrm{~cm}$ distance. The lower clamp was held stationary while the film was stretched apart by moving the upper clamp at a speed of $2.0 \mathrm{~mm} / \mathrm{s}$ until the film tore. According to the test parameters fed to TexturePro-CT Software (V1.3 Build 14) at the suitable mode, the stretching force (maximum stress) applied onto the film at the point when it broke was recorded by the system as the tensile strength. ${ }^{31}$

\section{Disintegration time of films}

The disintegration time of the prepared oral films was determined using the petri dish. For that, three randomly selected $(2 \times 2 \mathrm{~cm})$ film samples of each formula were separately added on to the surface of $2 \mathrm{~mL}$ phosphate buffer ( $\mathrm{pH}$ 6.8) in a petri dish at $37^{\circ} \mathrm{C} \pm 0.5^{\circ} \mathrm{C}$. Dishes were occasionally subjected to gentle swirling for 5 seconds until complete film breaking up. The time elapsed until complete film breaking was recorded as the disintegration time..$^{23}$

\section{In vitro dissolution studies}

The drug release rate from the prepared oral films was studied in the United States Pharmacopeia XXIV dissolution testing apparatus II (UDT-804 paddle dissolution apparatus; United 
States Pharmacopeia, North Bethesda, MD, USA). For that, film sample $(2 \times 2 \mathrm{~cm})$ of each formula was added to $250 \mathrm{~mL}$ of phosphate buffer ( $\mathrm{pH}$ 6.8) dissolution medium maintained at $37^{\circ} \mathrm{C} \pm 0.5^{\circ} \mathrm{C}$ and stirred at $50 \mathrm{rpm}$. At predetermined time intervals $(0,5,10,15,20$, and 30 minutes $), 5 \mathrm{~mL}$ sample was withdrawn with replacement. The absorbance of the drug was spectrophotometrically measured at $281 \mathrm{~nm}$ which was experimentally determined as the $\operatorname{drug} \lambda_{\max }$ (Shimadzu UV/Vis double beam spectrophotometer) after filtration on $0.45 \mu \mathrm{m}$ membrane filter. The cumulative percentage of drug release was calculated using an equation obtained from previously constructed standard calibration curve. ${ }^{32}$ For comparison, the dissolution rate of plain drug and its release rate from conventional alginate films (prepared using the same excipients) were also determined. The mean of six determinations was considered.

\section{Drug content}

Three randomly selected films of each optimized formula were separately transferred to $250 \mathrm{~mL}$ stoppered conical flask and $100 \mathrm{~mL}$ methanol was added. ${ }^{32}$ Solutions were shaken for 24 hours followed by sonication for 15 minutes. The drug absorbance was spectrophotometrically measured at $\lambda_{\max } 281 \mathrm{~nm}$ (Shimadzu UV/Vis double beam spectrophotometer) after filtration on 0.45 membrane filter and the drug content was calculated using an equation obtained from previously constructed standard calibration curve in methanol. Average value of drug content in the three tested samples was recorded with standard deviation.

\section{Folding endurance}

Three film samples of each optimized formula were repeatedly folded at the same place until the sample was broken. The number of times the film was folded in the same plane before breaking was recorded, and the average of the three film determinations was considered as the value of the film folding endurance. ${ }^{31}$

\section{Percentage elongation}

As previously described the tensile strength was determined using Brookfield CT-3 Texture Analyzer equipped by TA-DE fixture probe (CT3-10,000 load cell model; Brookfield Engineering Lab. Inc.). The percentage elongation was determined by the TexturePro-CT Software (V1.3 Build 14) as the maximum film length just before it breaks. ${ }^{23}$ The recorded value was also an average of three determinations.

\section{Film $\mathrm{pH}$ determination}

In this work both film solution $\mathrm{pH}^{23}$ and surface $\mathrm{pH}^{33}$ were measured. For film solution $\mathrm{pH}$, three film samples of each optimized formula were separately dissolved in $10 \mathrm{~mL}$ of distilled water and the $\mathrm{pH}$ of the resulting solution was measured using a standardized $\mathrm{pH}$ meter (SevenExcellence $\mathrm{pH} / \mathrm{mV}$ meter; Mettler Toledo, Columbus, OH, USA). For the $\mathrm{pH}$ determination of the film surface, films were wetted with minimum water volume $(5 \mu \mathrm{L})$ and left for 1 minute. The $\mathrm{pH}$ electrode was placed in close contact with the wetted film surface at different points. The recorded values were an average of three determinations.

\section{Determination of moisture content}

Moisture content ( $\%$ ) of the optimized formulations was determined using Karl Fisher titration method using Karl Fischer 787 KF Titrino (Metrohm AG, Herisau, Schweiz, Switzerland). Water content of each film was determined based on the titration volume $(\mathrm{mL})$.

\section{Solid state characterizations and compatibility studies}

Depending on the previous optimization and evaluation results, one REP-AHAD oral film formula was selected and subjected to solid state characterizations and compatibility studies in comparison with plain drug, and the main formula components are as follows. ${ }^{34}$

\section{Differential scanning calorimetric (DSC) studies}

Suitable amounts of the tested samples were separately purged with continuous nitrogen gas in aluminum pan of differential scanning calorimeter (PerkinElmer DSC4; PerkinElmer Inc., Waltham, MA, USA) calibrated with ultrapure indium standard over a temperature range of $\left(25^{\circ} \mathrm{C}-300^{\circ} \mathrm{C}\right)$ with a heating rate of $10^{\circ} \mathrm{C} / \mathrm{min}$. DSC thermograms were recorded and analyzed.

\section{Infrared (IR) spectroscopy}

Suitable amounts of the tested samples were scanned in the range of 4,000 to $500 \mathrm{~cm}^{-1}$ at room temperature using IR spectrophotometer (Shimadzu IR-435; Shimadzu, Kyoto, Japan) after compression with dry potassium bromide powder under pressure of 10,000-15,000 $\mathrm{psi}^{2}$ IR spectra were recorded and analyzed.

\section{Surface morphological studies}

The surface morphology of the optimized formula was examined by SEM (model JEOL JSM-6360; JEOL, Tokyo, Japan) in comparison with alginate oral film (prepared with same excipients). Samples were located onto adhesive carbonized tape on aluminum stubs and coated with a thin gold layer 
(30Å) using POLARON-E 3000 sputter coater. At suitable $\mathrm{KV}$, images were recorded under suitable magnification with direct data capture onto a computer.

\section{In vivo and bioavailability studies}

The study protocol was reviewed and approved by the research ethics committee of Taif University (approval \# 38-38-0028). All experimental procedures in animals complied with Taif University ethical guidelines for biomedical research.

The optimized REP-AHAD film formula (treatment A) was subjected to further in vivo evaluation in comparison with the prepared conventional alginate film (treatment B) and oral plain drug (treatment $\mathrm{C}$ ) in rabbits.

\section{Study design}

In this work, a single-dose bioavailability study was applied on three phases according to a randomized crossover design to discuss the study protocol and information about drug bioavailability in 18 healthy male albino rabbits $(2.5-3.0 \mathrm{~kg})$ divided into three groups $(n=6)$. Animals were kept on the same diet during the study, with overnight fasting before drug administration with free access to water. All rabbits were cannulated through the marginal ear vein to allow easy blood collection and received the suitable animal dose as calculated with reference to Paget and Barnes table. ${ }^{35}$ Plasma sample $(2 \mathrm{~mL})$ was withdrawn as a control from each rabbit before drug administration.

For administration of treatments $\mathrm{A}$ and $\mathrm{B},{ }^{36}$ animals were anesthetized according to the guidelines on anesthesia and analgesia in rabbits ${ }^{37}$ and placed on a flat bench supporting the lower jaw in a fixed position. The tested film was placed on the animal's tongue after slight wetting with $30 \mu \mathrm{L}$ of water. A suitable weight of plain REP (treatment $\mathrm{C}$ ) equivalent to the calculated animal dose was orally administered to the animal after suspension in minimal water volume by the aid of gastric gavage.

Blood samples $(2 \mathrm{~mL})$ were collected at $5(0.0834)$, 10 (0.167), 15 (0.25), 30 (0.5), 60 (1), 90 (1.5), 120 (2), 150 (2.5), 180 (3), 240 (4), 360 (6) and 480 (8) minutes (hours) post dose in heparinized tubes and immediately centrifuged at 3,000 rpm for 10 minutes. Plasma was transferred to another pre-labeled polypropylene screw-cap tubes and frozen at $-20^{\circ} \mathrm{C}$ until analysis.

\section{Determination of REP in plasma}

Drug concentration in the collected plasma samples was determined using a validated, sensitive liquid chromatography/ tandem mass spectrometry (LC-MS/MS) method, briefly described as follows. ${ }^{38}$

\section{Chromatographic conditions}

A $70: 30 \mathrm{v} / \mathrm{v}$ acetonitrile:ammonium acetate buffer $(0.01 \mathrm{M}$, pH 6.8) mobile phase was injected into the liquid chromatography unit equipped by Zorbax Eclipse XDB-C18 column (100 A, $5 \mu \mathrm{m}, 4.6 \times 150 \mathrm{~mm}$ ) after degasing at a flow rate of $1.2 \mathrm{~mL} / \mathrm{min}$ at $35^{\circ} \mathrm{C}$. The mass spectrometer's electrospray ionization chamber operated in positive ion mode (API 4000 mass spectrometer; Applied Biosystems Sciex, Ontario, Canada). The ion spray voltage was set at 4,000 V, nebulizer pressure $45 \mathrm{psi}$, and drying gas (nitrogen) flow rate of $10 \mathrm{~L} / \mathrm{min}$, at $450^{\circ} \mathrm{C}$ source temperature. Quantitation was achieved using diazepam as an internal standard on a QT mass detector.

\section{Sample preparation}

All frozen plasma samples were thawed at ambient temperature and prepared for work by solvent extraction method as follows: In $5 \mathrm{~mL}$ glass tube, $25 \mu \mathrm{L}$ plasma sample was mixed with $25 \mu \mathrm{L}$ methanolic internal standard solution, $25 \mu \mathrm{L}$ methanol: water $(50: 50 \mathrm{v} / \mathrm{v})$ and $3 \mathrm{~mL}$ diethyl ether-dichloromethane $(60: 40 \mathrm{v} / \mathrm{v})$. The mixture was vortexed for 1 minute then centrifuged at 4,000 rpm for further 5 minutes, and the supernatant layer was separated into a clean glass tube and gently dried under nitrogen at $40^{\circ} \mathrm{C}$. The dried residue was reconstituted in $100 \mu \mathrm{L}$ mobile phase, and $20 \mu \mathrm{L}$ sample was directly injected into the Liquid Chromatography Mass Spectrometry apparatus system using the autosampler. Drug concentration was calculated with reference to the data obtained from the constructed calibration curve in plasma.

\section{Pharmacokinetics calculations}

Plasma concentration-time curves were constructed, and the pharmacokinetic parameters [namely $\mathrm{C}_{\max }(\mu \mathrm{g} / \mathrm{mL}), \mathrm{T}_{\max }$ (hour, h), $\mathrm{AUC}_{0-8}$ and $\mathrm{AUC}_{0-\infty}(\mu \mathrm{g} \cdot \mathrm{h} / \mathrm{mL}), \mathrm{K}_{\mathrm{el}}\left(\right.$ hour $^{-1}, \mathrm{~h}^{-1}$ ), and $t_{1 / 2}($ hour, $\left.h)\right]$ for each rabbit were calculated and manipulated using WinNonlin Professional 4.0.1 software (Pharsight Corp., Cary, NC, USA).

\section{Statistical analysis of pharmacokinetic data}

The mean pharmacokinetic parameters were statistically analyzed using post hoc one-way ANOVA test (Tukey mode) at $P$-value $>0.05$, and the confidence intervals were calculated (IBM Incorporation, Armonk, NY, USA).

\section{Results and discussion Statistical analysis of experimental data}

The experimental design describes the applied statistical planning of different experiments to determine the main variables that significantly affect and control a certain targeted 
response and also assess their suitable level. It also gives the advantage of reducing process variation and maximizes the obtained results without need for further inspection. ${ }^{39}$

Box-Behnken statistical experimental design was applied in this study because it is an optimum design to study the interactive (quadratic) effects between factors and deriving second-order polynomial equations with relatively few experimental runs in comparison with other similar designs. ${ }^{40}$ Response surface models may contain only two-level main effects (additive - linear) that are expressed by linear and linear 2FI models or may also include nonadditive, threelevel (quadratic) and four-level (cubic) interactive effects that represent curvature or cubic plots; the equation describes the non-linear quadratic model and is expressed as:

$$
\begin{aligned}
\mathrm{R}= & \mathrm{b} 0+\mathrm{b} 1 \mathrm{~A}+\mathrm{b} 2 \mathrm{~B}+\mathrm{b} 3 \mathrm{C}+\mathrm{b} 12 \mathrm{AB}+\mathrm{b} 13 \mathrm{AC} \\
& +\mathrm{b} 23 \mathrm{BC}+\mathrm{b} 11 \mathrm{~A}^{2}+\mathrm{b} 22 \mathrm{~B}^{2}+\mathrm{b} 33 \mathrm{C}^{2}
\end{aligned}
$$

where $\mathrm{R}$ is response, $\mathrm{b} 0$ is intercept, and $\mathrm{b} 1-\mathrm{b} 33$ are regression coefficients. $\mathrm{A}, \mathrm{B}$, and $\mathrm{C}$ are the independent variables. The terms $\mathrm{AB}, \mathrm{AC}$, and $\mathrm{BC}$ and $\mathrm{A}^{2}, \mathrm{~B}^{2}$, and $\mathrm{C}^{2}$ represent the interaction and quadratic terms, respectively. ${ }^{41}$

According to Box-Behnken design, 17 REP-AHAD oral film formulae were prepared by solvent casting technique. As presented in Table 2, results showed that the interactive effect of different combinations of the selected independent factors at different levels resulted in different observed responses for release rate, tensile strength, and disintegration time that reflected high dependency of responses on the selected independent factors values.

Fitting of data to different mathematical model equations suggested the quadratic model to describe the three responses with higher $\mathrm{R}^{2}$ coefficients (for both adjusted and predicted) and significant terms at the selected $P$-value when compared to other models. The small value of SD for the calculated coefficients indicates the strength of the proposed nonlinear correlation between the dependent factors and the observed responses (Table 3).

Factors affecting experimental results may be controllable or uncontrollable, the latter may be a causative agent for variability and usually described as noise. ${ }^{39}$ In Box-Behnken design, noise is defined in terms of adequate precision; value $>4$ is desirable and indicates low noise signal. According to the results presented in Table 3 , the recorded values were $8.24,44.023$, and 12.323 for $R_{1}, R_{2}$, and $R_{3}$, respectively, indicating an adequate signal and confirm the suitability of the suggested model to describe the proposed experimental design.

According to the statistical ANOVA results presented in Table 4, the derived polynomial equations showed model F-values of $8.23,161.67$, and 11.44 with probability of $<0.05$ for $R_{1}, R_{2}$, and $R_{3}$, respectively, indicating validity of these equations and significance of the suggested quadratic model for all responses. The small $P$-values for the three responses $(0.54 \%, 0.01 \%$, and $0.2 \%$, respectively) support the previously deduced results of adequate precision and confirm low noise signal.

\begin{tabular}{|c|c|c|c|c|c|c|}
\hline Formula & $\begin{array}{l}\text { A AHAD } \\
(\% \mathrm{w} / w)\end{array}$ & $\begin{array}{l}\text { B plasticizer } \\
(\% \mathrm{w} / \mathrm{w})\end{array}$ & $\begin{array}{l}\text { C disintegrant } \\
(\% \mathrm{w} / \mathrm{w})\end{array}$ & $\begin{array}{l}R_{1} \text { release rate } \\
(\% \mathrm{w} / v)\end{array}$ & $\begin{array}{l}R_{2} \text { tensile } \\
\text { strength }\left(\mathrm{g} / \mathrm{cm}^{2}\right)\end{array}$ & $\begin{array}{l}\mathbf{R}_{3} \text { disintegration } \\
\text { time (seconds) }\end{array}$ \\
\hline $\mathrm{FI}$ & 2.00 & 20.00 & 10.00 & 88.42 & 117.18 & 20 \\
\hline $\mathrm{F} 2$ & 1.00 & 30.00 & 10.00 & 89.88 & 101.92 & 23 \\
\hline $\mathrm{F} 3$ & 1.00 & 20.00 & 15.00 & 90.98 & 105.76 & 18 \\
\hline $\mathrm{F} 4$ & 2.00 & 20.00 & 10.00 & 91.93 & 116.83 & 20 \\
\hline F5 & 2.00 & 20.00 & 10.00 & 88.27 & 116.92 & 19 \\
\hline F6 & 1.00 & 20.00 & 5.00 & 91.62 & 96.99 & 27 \\
\hline F7 & 2.00 & 20.00 & 10.00 & 90.79 & 117.24 & 21 \\
\hline F8 & 2.00 & 10.00 & 15.00 & 93.11 & 126.88 & 19 \\
\hline F9 & 3.00 & 20.00 & 15.00 & 97.24 & 142.86 & 23 \\
\hline FIO & 2.00 & 20.00 & 10.00 & 90.19 & 116.79 & 22 \\
\hline FII & 2.00 & 30.00 & 5.00 & 94.41 & 114.68 & 25 \\
\hline $\mathrm{FI} 2$ & 3.00 & 30.00 & 10.00 & 96.95 & 137.98 & 23 \\
\hline $\mathrm{FI} 3$ & 2.00 & 30.00 & 15.00 & 92.7I & 119.23 & 20 \\
\hline FI4 & 1.00 & 10.00 & 10.00 & 88.84 & 112.87 & 24 \\
\hline FI5 & 2.00 & 10.00 & 5.00 & 89.28 & $|24.9|$ & 27 \\
\hline FI6 & 3.00 & 20.00 & 5.00 & 97.98 & 135.92 & 24 \\
\hline FI7 & 3.00 & 10.00 & 10.00 & 97.86 & 147.82 & 23 \\
\hline
\end{tabular}

Table 2 Box-Behnken experimental design and their observed responses

Abbreviation: AHAD, alginate hexyl amide derivative. 
Table 3 Regression analysis results for the response surface quadratic model

\begin{tabular}{|c|c|c|c|c|c|c|c|}
\hline \multirow[t]{2}{*}{ Formula } & \multicolumn{6}{|c|}{ REP-AHAD oral film formulae } & \multirow[t]{2}{*}{ Remarks } \\
\hline & $\mathbf{R}^{2}$ & Adjusted $\mathbf{R}^{2}$ & Predicted $\mathbf{R}^{2}$ & SD & CV\% & $\begin{array}{l}\text { Adequate precision } \\
\text { for ANOVA }\end{array}$ & \\
\hline \multicolumn{8}{|l|}{$\mathrm{R}_{1}$} \\
\hline Linear model & 0.5837 & 0.4877 & 0.3415 & 2.41 & & & \\
\hline $2 \mathrm{FI}$ model & 0.6311 & 0.4097 & -0.0108 & 2.59 & & & \\
\hline Quadratic model & $\underline{0.9145}$ & $\underline{0.8046}$ & $\underline{0.4143}$ & 1.49 & 1.61 & 8.240 & Suggested \\
\hline Cubic model & 0.9458 & 0.7833 & - & 1.57 & & & Aliased \\
\hline \multicolumn{8}{|l|}{$\mathrm{R}_{2}$} \\
\hline Linear model & 0.9461 & 0.9337 & 0.9091 & 3.6 & & & \\
\hline $2 \mathrm{FI}$ model & 0.9470 & 0.9152 & 0.8189 & 4.07 & & & \\
\hline Quadratic model & $\underline{0.9952}$ & $\underline{0.9891}$ & $\underline{0.9242}$ & 1.46 & 1.21 & 44.023 & Suggested \\
\hline Cubic model & 0.9999 & 0.9998 & - & 0.21 & & & Aliased \\
\hline \multicolumn{8}{|l|}{$\mathrm{R}_{3}$} \\
\hline Linear model & 0.5702 & 0.4710 & 0.2820 & 1.97 & & & \\
\hline 2FI model & 0.7283 & 0.5652 & 0.3587 & 1.78 & & & \\
\hline Quadratic model & 0.9364 & $\underline{0.8545}$ & $\underline{0.6231}$ & 1.03 & 4.64 & 12.323 & Suggested \\
\hline Cubic model & 0.9556 & 0.8223 & - & 1.14 & & & Aliased \\
\hline
\end{tabular}

Note: Underlined entries refer to "the best fit model terms".

Abbreviations: REP, repaglinide; AHAD, alginate hexyl amide derivative; $2 \mathrm{FI}$, two-factor interaction.

For further exploring the quantitative effect of different factors on the desired response, 3D response surface and perturbation plots were constructed (Figures 1-3). These plots allow the study of interactive effect of two factors on specified response at constant level of the third factor.

\section{REP release rate studies}

According to the results in Table 2, and presented in Figure 1, the percentage drug release ranged from $88.27 \%$ (F5) to $97.98 \%$ (F16) within 30 minutes depending on the different factor levels. The derived quadratic equation that describes the effect of different factors on drug release rate is:

$$
\begin{aligned}
R_{1}= & 89.92+3.59 A+0.61 B+0.094 C \\
& -0.49 A B-0.025 A C-1.38 \mathrm{BC}+2.77 \mathrm{~A}^{2} \\
& +0.69 \mathrm{~B}^{2}+1.77 \mathrm{C}^{2}
\end{aligned}
$$

ANOVA results showed that only $\mathrm{A}, \mathrm{A}^{2}$, and $\mathrm{C}^{2}$ were the model terms that significantly affect the drug release rate from the prepared oral films with $P$-values $<5 \%$. A factor coefficient with a positive value indicated proportional relation between the factor level (concentration) and the corresponding response value.

It was observed that increasing AHAD concentration causes a nonlinear significant rise in the drug release rate from $88.84 \%$ to $97.86 \%$ (at least B level) and $89.88 \%$ to $96.95 \%$ (at highest B level) when $\mathrm{C}$ is constant (Figure 1A) in comparison with the rate of increase from $91.62 \%$ to $97.98 \%$ (at least $\mathrm{C}$ level) and $90.98 \%$ to $97.24 \%$ (at highest C level) when B is hold constant (Figure 1B). This could be explained by the surface active nature of the AHAD that increases the drug subdivision and wettability within the

\begin{tabular}{|c|c|c|c|c|c|c|}
\hline \multirow[t]{3}{*}{ Source } & \multicolumn{6}{|c|}{ Quadratic model } \\
\hline & \multicolumn{2}{|c|}{ Release rate $\left(R_{1}\right)$} & \multicolumn{2}{|c|}{ Tensile strength $\left(\mathbf{R}_{2}\right)$} & \multicolumn{2}{|c|}{ Disintegration time $\left(\mathbf{R}_{3}\right)$} \\
\hline & F-value & $P$-value & F-value & $P$-value & F-value & $P$-value \\
\hline Model & 8.23 & $0.0054 *$ & 161.67 & $<0.0001 *$ & $\mathrm{I} \mathrm{l} .44$ & $0.0020 *$ \\
\hline A & 44.43 & $0.0002 *$ & $1,266.73$ & $<0.0001 *$ & 0.12 & 0.7419 \\
\hline B & 1.33 & 0.2866 & 87.61 & $<0.0001 *$ & 0.47 & $0.515 \mathrm{I}$ \\
\hline $\mathrm{C}$ & 0.032 & 0.8638 & 28.95 & $0.0010^{*}$ & 62.13 & $0.000 I^{*}$ \\
\hline$A B$ & 0.043 & 0.5337 & 0.14 & 0.7152 & 0.23 & 0.6427 \\
\hline$A C$ & I.127E-003 & 0.9742 & 0.39 & 0.5509 & 15.03 & $0.006 I^{*}$ \\
\hline $\mathrm{BC}$ & 3.45 & 0.1058 & 0.78 & 0.4065 & 2.11 & 0.1893 \\
\hline$A^{2}$ & 14.56 & $0.0066^{*}$ & 24.96 & $0.0016^{*}$ & 9.50 & $0.0177^{*}$ \\
\hline $\mathrm{B}^{2}$ & 0.91 & 0.3719 & 41.74 & $0.0003^{*}$ & 6.69 & $0.0362^{*}$ \\
\hline$C^{2}$ & 5.91 & $0.0453^{*}$ & 0.054 & 0.8223 & 4.36 & $0.075 \mathrm{I}$ \\
\hline Lack of fit & 1.9 & 0.5675 & 116.44 & $0.0002 *$ & 0.58 & 0.6603 \\
\hline
\end{tabular}
prepared film. ${ }^{30}$ Simultaneous increase of disintegrant or

Table 4 ANOVA results for different formula variables according to the best fit model

Note: *Significant model terms. 
A

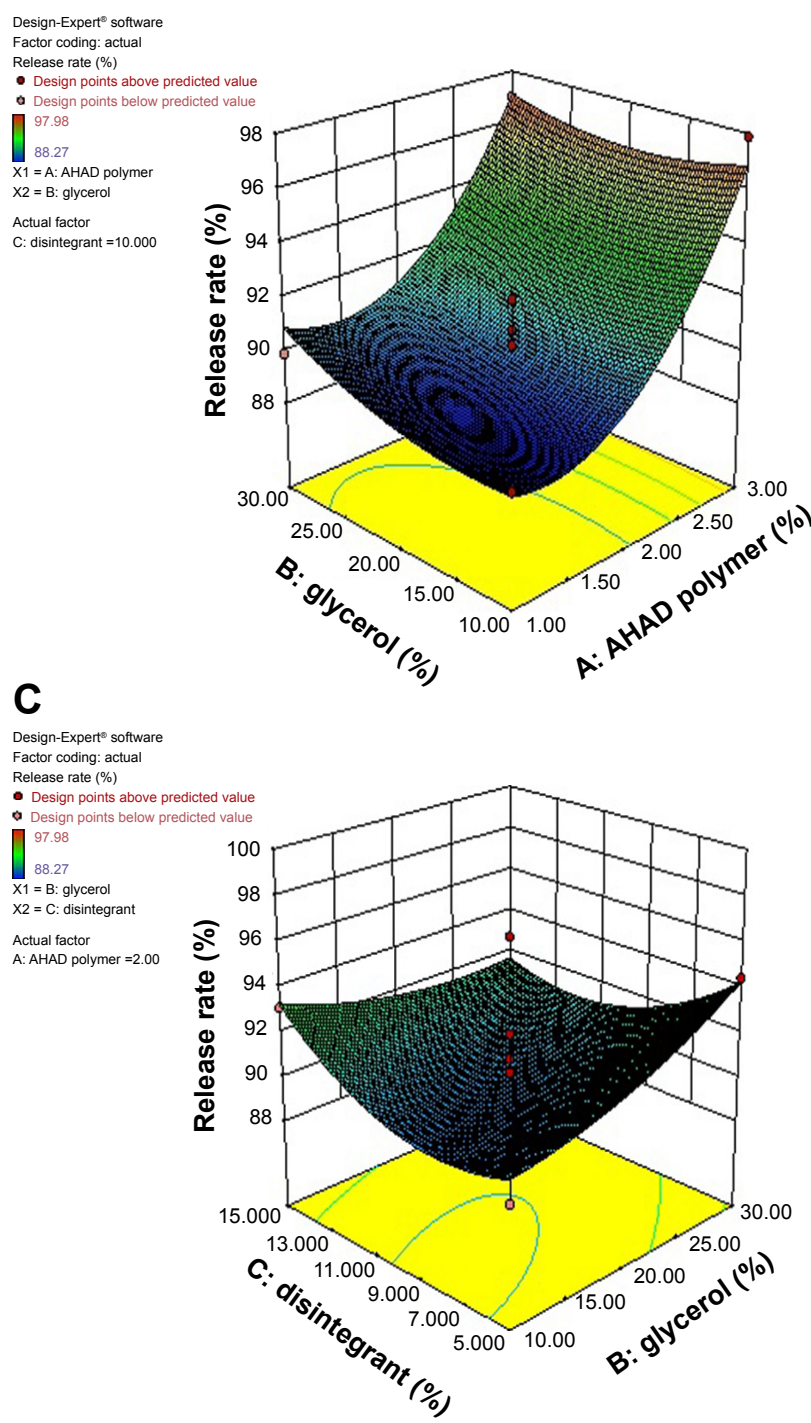

B

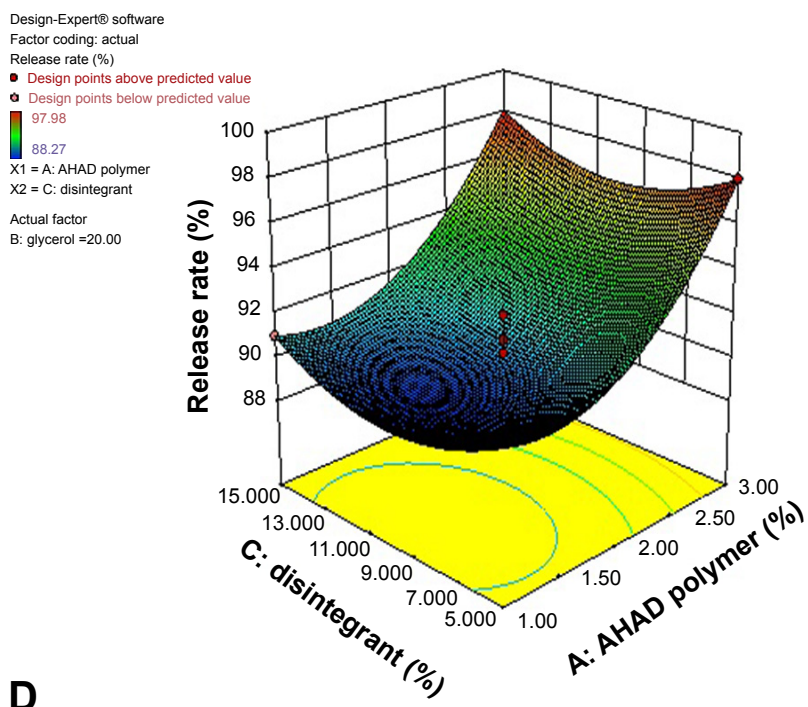

Design-Expert ${ }^{\oplus}$ software Factor coding: actual Release rate (\%)

Actual factors A: AHAD polymer $=2.00$ B: glycerol $=20.00$

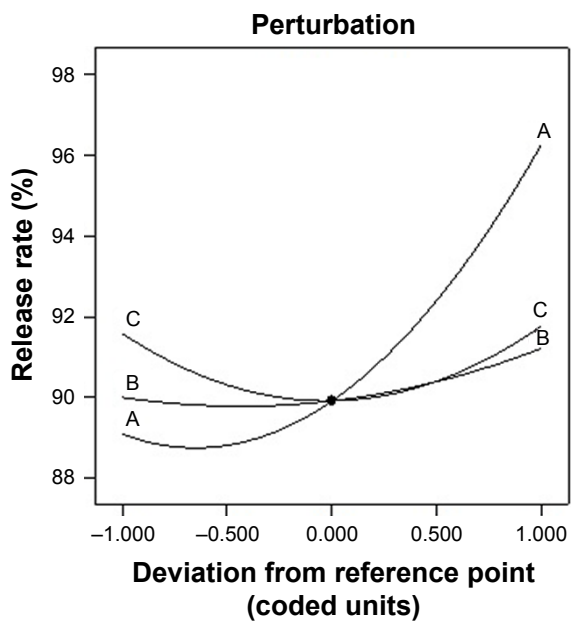

Figure I Three dimensional response surface $(\mathbf{A}-\mathbf{C})$ and perturbation plot $(\mathbf{D})$ showing the effect of different independent variables on REP release rate $\left(\mathrm{R}_{1}\right)$. Abbreviations: REP, repaglinide; AHAD, alginate hexyl amide derivative.

plasticizer concentration with AHAD concentration showed negligible effect on drug release rate as confirmed by their insignificant coefficient terms. The high coefficient value of A reflects that increasing polymer concentration had more significant effect on drug release rate while the small coefficient value of $\mathrm{C}^{2}$ reflects the least significant action. Further investigation of the perturbation plot to compare the effect of the three factors at specified point (Figure 1D) showed that AHAD concentration (A) had a major effect on drug release rate followed by minor disintegrant effect $(\mathrm{C})$ and finally negligible effect of plasticizer concentration (B).

\section{Tensile strength studies}

Non-brittle, soft, and stretchable characteristics are major targets during oral film preparation. ${ }^{27}$ For the prepared oral film formulae, the tensile strength ranged from $101.92 \mathrm{~g} / \mathrm{cm}^{2}$ (F2) to $147.82 \mathrm{~g} / \mathrm{cm}^{2}$ (F17). The quadratic equation generated to correlate the main and interaction effects of different factors to the recorded tensile strength is:

$$
\begin{aligned}
R_{2}= & 116.99+18.38 A-4.83 B+2.78 C+0.28 A B \\
& -0.46 A C+0.64 B C+3.56 A^{2}+4.60 B^{2}-0.17 C^{2}
\end{aligned}
$$

Only the model terms A, B, C, $\mathrm{A}^{2}$, and $\mathrm{B}^{2}$ were significant according to the AVOVA results with $P$-values $<5 \%$ (Table 3 ).

AHAD concentration showed positive effect on tensile strength as indicated by the positive value of its coefficient in the quadratic nonlinear model equation. The far higher value of its coefficient in comparison with other significant factor coefficients is an indication that $\mathrm{A}$ has the major 


\section{A}

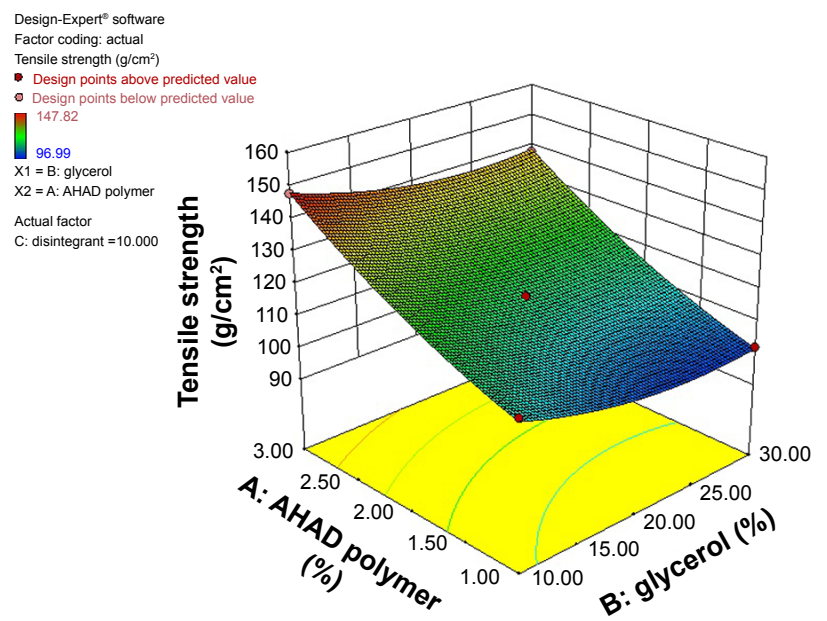

\section{C}

Design-Expert software Factor coding: actual
Tensile strength $\left(\mathrm{g} / \mathrm{cm}^{2}\right)$ Tensile strength $\left(\mathrm{g} / \mathrm{cm}^{2}\right)$ - Design points above predicted value - Design X6.99 $\mathrm{X} 2=\mathrm{C}:$ disintegrant Actual factor A. AHAD polym

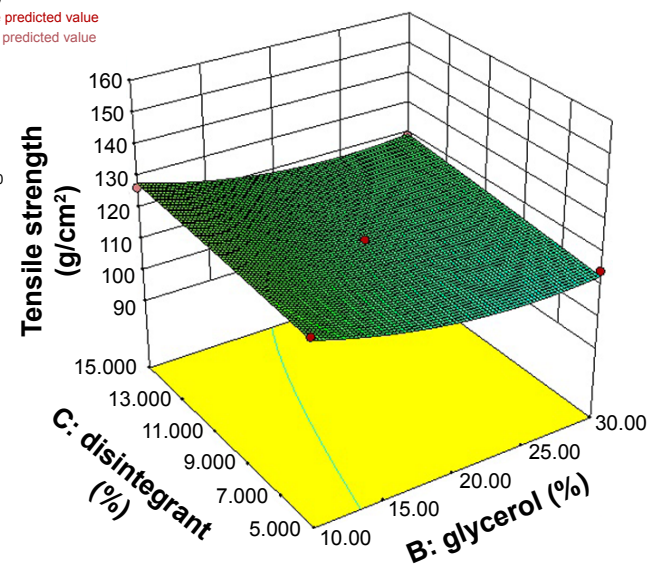

B

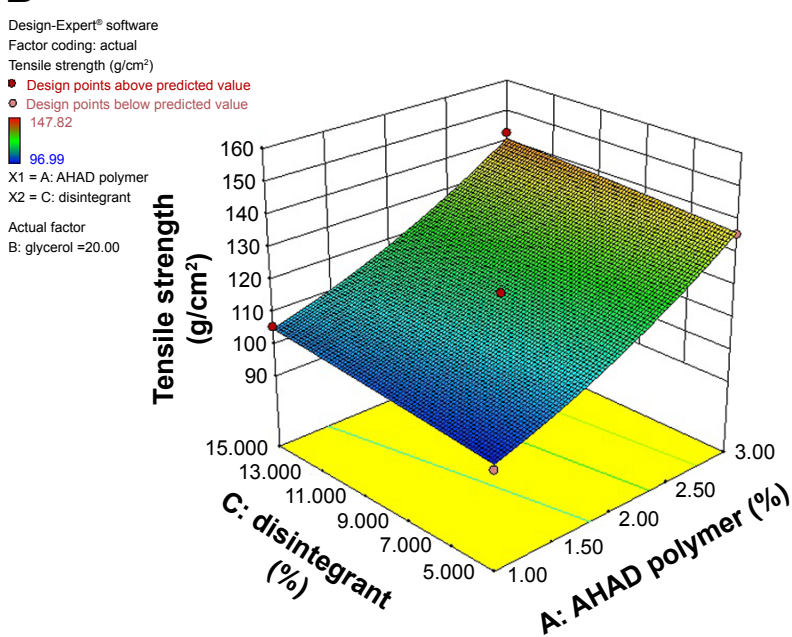

D

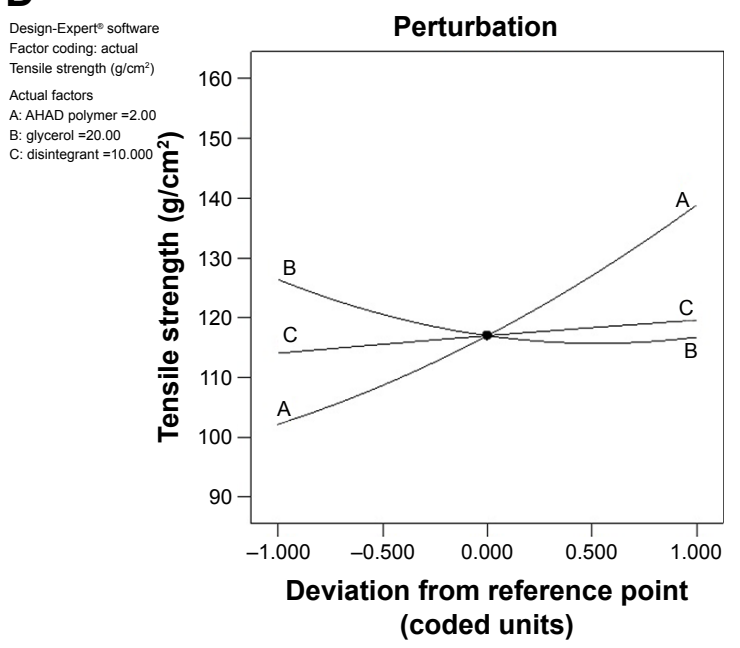

Figure 2 Three dimensional response surface $(\mathbf{A}-\mathbf{C})$ and perturbation plot $(\mathbf{D})$ showing the effect of different independent variables on tensile strength $\left(R_{2}\right)$. Abbreviations: REP, repaglinide; AHAD, alginate hexyl amide derivative.

significant effect on tensile strength that can be referred to the high elasticity nature of the AHAD as film forming polymer, where the polymer chain flexibility improved due to decreasing carboxyl moieties by hexyl amidation. ${ }^{42}$ Figure 2A shows that the tensile strength was increased from 112.87 to $147.82 \mathrm{~g} / \mathrm{cm}^{2}$ (at least B level) and 101.92 to $137.98 \mathrm{~g} / \mathrm{cm}^{2}$ (at highest B level) when $\mathrm{C}$ is hold constant. Figure 2B shows that tensile strength increased from 96.99 to $135.92 \mathrm{~g} / \mathrm{cm}^{2}$ (at least $\mathrm{C}$ level) and 105.76 to $142.86 \mathrm{~g} /$ $\mathrm{cm}^{2}$ (at highest C level) when B is hold constant. Results also indicated that the disintegrant concentration had minor positive effect on tensile strength that increased from 96.99 to $105.76 \mathrm{~g} / \mathrm{cm}^{2}$ (at least A level) and from 135.92 to $142.86 \mathrm{~g} / \mathrm{cm}^{2}$ (at highest A level) when B is kept constant (Figure 2B) and from 124.91 to $126.88 \mathrm{~g} / \mathrm{cm}^{2}$ (at least $\mathrm{B}$ level) and from 114.86 to $119.23 \mathrm{~g} / \mathrm{cm}^{2}$ (at highest B level) when A is kept constant (Figure 2C). The small positive value of the $\mathrm{C}$ coefficient confirms the previous results. These results could be correlated to increasing film thickness due to disintegrant addition.

The liquid nature of glycerin (as plasticizer) and may be the use of inappropriate amount had negative effect on the tensile strength. Figure $2 \mathrm{~A}$ and $\mathrm{C}$ show that increasing plasticizer concentration led to lowering the tensile strength as indicated by the negative sign of its coefficient in the equation model, and these results are in accordance with those obtained by Liew et al, ${ }^{43}$ where incorporation of plasticizer reduced tensile strength but increased elasticity of the orodispersible films (ODF) formed. Perturbation plot (Figure 2D) confirmed that AHAD concentration (A) still had the major effect on film properties including tensile strength followed by plasticizer concentration (B) and that disintegrant concentration (C) also still keeps minor and least significant effect on film properties. 
A

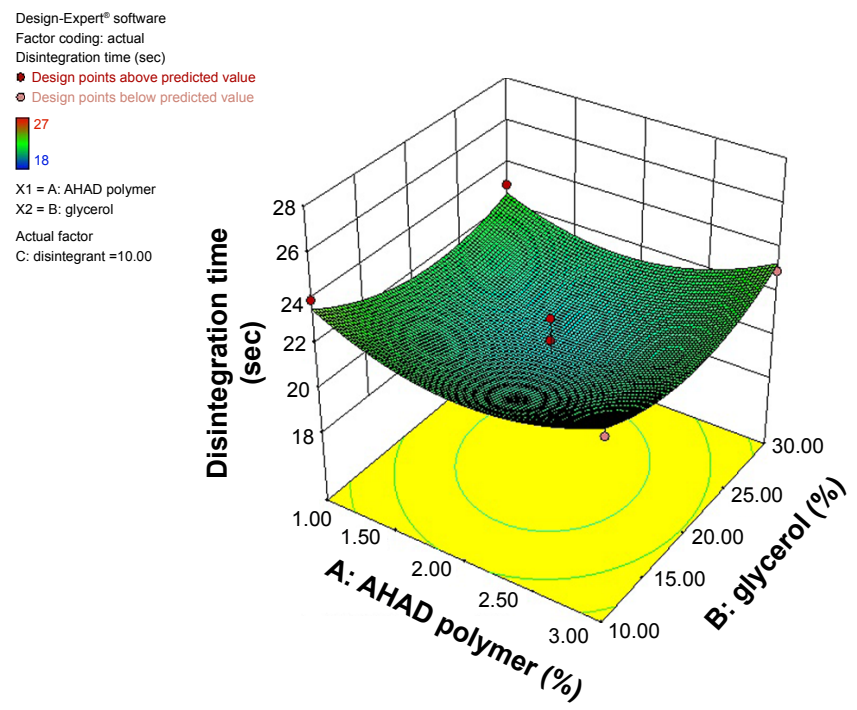

C

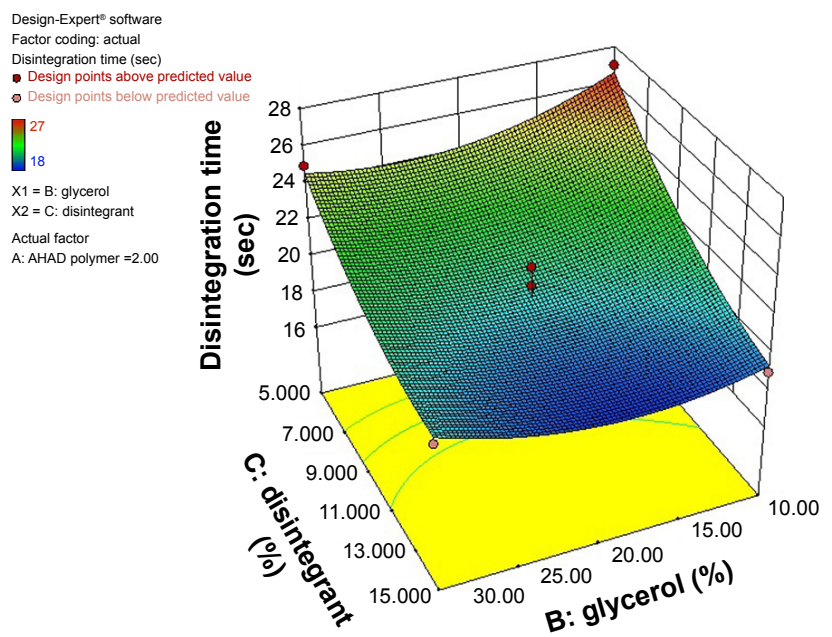

B

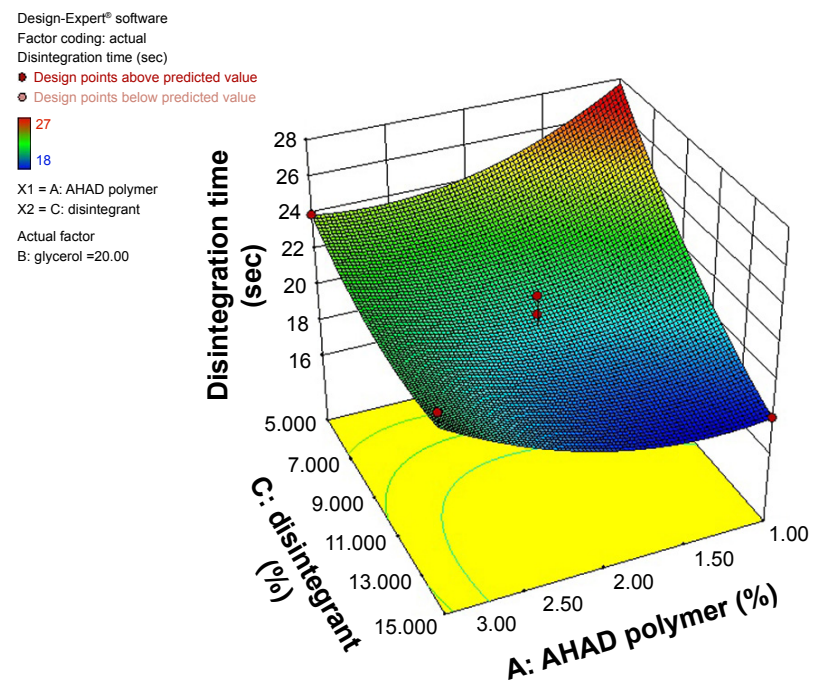

D
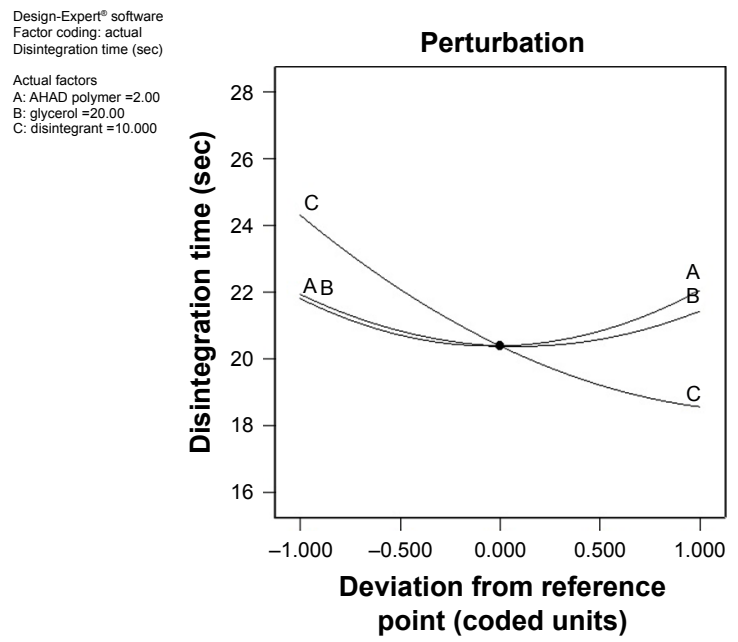

Figure 3 Three dimensional response surface $(\mathbf{A}-\mathbf{C})$ and perturbation plot $(\mathbf{D})$ showing the effect of different independent variables on disintegration time $\left(\mathbf{R}_{3}\right)$. Abbreviations: REP, repaglinide; AHAD, alginate hexyl amide derivative.

\section{Disintegration time studies}

The quadratic equation that describes the disintegration time of the prepared oral film is:

$$
\begin{aligned}
\mathrm{R}_{3}= & 20.40+0.13 \mathrm{~A}-0.25 \mathrm{~B}-2.88 \mathrm{C}+0.25 \mathrm{AB} \\
& +2.00 \mathrm{AC}+0.75 \mathrm{BC}+1.55 \mathrm{~A}^{2}+1.30 \mathrm{~B}^{2}+1.05 \mathrm{C}^{2}
\end{aligned}
$$

The recorded disintegration time was rapid in the range of 18 seconds (F3) to 27 seconds (F15) which reflects the accuracy of the proposed disintegrant concentrations and suitability of the prepared films for buccal use. Results in Table 3 show that only $\mathrm{C}, \mathrm{AC}, \mathrm{A}^{2}$, and $\mathrm{B}^{2}$ represent the significant model terms with F-values $<0.05$.

The negative value of $\mathrm{C}$ coefficient indicated that in vitro disintegration time of the prepared oral films significantly decrease at higher super-disintegrant levels. Figure 3B shows the interactive effect $\mathrm{AC}$ on disintegration time, where at low AHAD concentration, increasing $\mathrm{C}$ from the low to high level caused shortening of disintegration time from 27 to 18 seconds. This effect was attenuated with increasing AHAD concentration, where only slight shortening of disintegration time from 24 to 23 seconds was observed with increasing disintegrant concentration at the maximum AHAD concentration, this could be explained by the resulted increase in film thickness due to higher AHAD concentrations. ${ }^{27}$

The effect of plasticizer concentration on disintegration time was also controlled by disintegrant concentration. Figure $3 \mathrm{C}$ shows that at low disintegrant concentration, the prepared films disintegrated rapidly at higher plasticizer level 
due to the hygroscopic nature of glycerin and increased film elasticity; the same results were observed by Liew et al, ${ }^{43}$ where disintegration time of film decreased with decreasing tensile strength of the film and increasing elasticity. This action is almost unnoticeable at higher disintegrant concentration that shortened the disintegration time to lower level and increased the plasticizer effect. The smallest coefficient of $\mathrm{B}^{2}$ reflected these results with least significant action observed. Results on the perturbation plot (Figure 3D) showed major significant positive effect for disintegrant concentration (C) on film disintegration time followed by minor AHAD concentration effect (A) and plasticizer concentration (B). Disintegration time of film decreased corresponding to decrease in tensile strength of the film.

\section{Optimization and validation of the collected data}

To test for the validity of the collected data and based on the higher desirability factor probed by design expert software, five oral film formulae attaining the optimum responses within the proposed constraints (maximum release rate and tensile strength, shortest disintegration time) were selected as check points by applying numerical point prediction optimization method available in the software. Results in Table 5 show that the collected results for the three responses were within the proposed constraint limits with excellent agreement with the predicted values as confirmed by the low prediction error percentage. Linear correlation was observed between the predicted and observed responses with high $\mathrm{R}^{2}(0.9435,0.9656$, and 0.99702$)$ for release rate, tensile strength, and disintegration time, respectively. These results indicate the validity of the proposed regression equation models and confirm the high ability of the experimental design to predict the optimum response at the selected variable levels.

\section{Evaluation of the prepared REP oral films}

Results in Table 6 show that the optimized film formulae were uniform, smooth, and flexible. The diameter ranged from 0.11 to $0.13 \mathrm{~mm}$ with low standard deviation indicating homogeneity and uniformity. Folding endurance and percentage elongation indicated film elasticity and resistance to brittleness, ${ }^{27}$ and the recorded data indicated that the optimized formulae had a very good flexibility to be bent from 139 to 142 times and high elongation capability to be stretched up to $16.23 \%$ of its original length mainly due to the positive effect of chemical modification on alginate molecule chain elasticity. The optimized oral films were almost neutral to eliminate any possibility of irritation to the buccal mucosa during administration. Results of moisture content indicated efficiency of the applied drying conditions. The high drug content $(97.776 \%-98.353 \%)$ could be correlated to the surface active nature of the film-forming polymer (AHAD) with solubilizing effect on the drug within the prepared film matrix. ${ }^{30}$

Figure 4 illustrates the dissolution profiles of REP from optimized AHAD films in comparison with plain drug and conventional alginate film. The release rate exceeded $80 \%$ from all formulae within 10 minutes up to about $90 \%$ within 15 minutes in comparison with $8.166 \%, 19.65 \%$ and $12.73 \%$, $29.67 \%$ for plain REP and alginate film within the same time, respectively. Maximum drug release was observed within 30 minutes $(96.47 \%, 96.99 \%, 96.29 \%, 97.79 \%$, and $96.68 \%$ )

Table 5 Composition of selected check points comparing predicted and observed values for different responses and prediction error percentage

\begin{tabular}{|c|c|c|c|c|c|c|c|c|}
\hline \multirow[t]{2}{*}{ Formula } & \multicolumn{3}{|c|}{ Composition } & \multirow[t]{2}{*}{ Response } & \multirow[t]{2}{*}{ Predicted } & \multirow[t]{2}{*}{ Observed } & \multirow{2}{*}{$\begin{array}{l}\text { Prediction } \\
\text { error (\%) }\end{array}$} & \multirow[t]{2}{*}{ Desirability } \\
\hline & $\mathbf{A}$ & B & C & & & & & \\
\hline $\mathrm{FI}$ & 2.77 & 10 & 15 & $\begin{array}{l}\mathrm{R}_{1} \\
\mathrm{R}_{2} \\
\mathrm{R}_{3}\end{array}$ & $\begin{array}{l}97.98 \\
144.0 \mid \\
21.723\end{array}$ & $\begin{array}{l}96.47 \\
140.42 \\
20.8\end{array}$ & $\begin{array}{l}1.54 \\
2.49 \\
4.25\end{array}$ & 0.916 \\
\hline F2 & 2.81 & 10.53 & 14.95 & $\begin{array}{l}R_{1} \\
R_{2} \\
R_{3}\end{array}$ & $\begin{array}{l}98.14 \\
144.24 \\
21.797\end{array}$ & $\begin{array}{l}96.99 \\
142.72 \\
21.3\end{array}$ & $\begin{array}{l}1.17 \\
1.05 \\
2.28\end{array}$ & 0.915 \\
\hline F3 & 2.83 & 10.68 & 14.64 & $\begin{array}{l}R_{1} \\
R_{2} \\
R_{3}\end{array}$ & $\begin{array}{l}97.98 \\
144.45 \\
21.858\end{array}$ & $\begin{array}{l}96.29 \\
144.29 \\
22\end{array}$ & $\begin{array}{l}1.73 \\
0.11 \\
-0.65\end{array}$ & 0.914 \\
\hline F4 & 2.85 & 10.95 & 15 & $\begin{array}{l}R_{1} \\
R_{2} \\
R_{3}\end{array}$ & $\begin{array}{l}98.44 \\
144.72 \\
21.916\end{array}$ & $\begin{array}{l}97.79 \\
145.86 \\
22.2\end{array}$ & $\begin{array}{l}0.65 \\
-0.79 \\
-1.29\end{array}$ & 0.913 \\
\hline F5 & 2.87 & 11.00 & 14.34 & $\begin{array}{l}\mathrm{R}_{1} \\
\mathrm{R}_{2} \\
\mathrm{R}_{3}\end{array}$ & $\begin{array}{l}97.98 \\
144.90 \\
21.972\end{array}$ & $\begin{array}{l}96.68 \\
146.33 \\
22.5\end{array}$ & $\begin{array}{l}1.33 \\
-0.99 \\
-2.41\end{array}$ & 0.912 \\
\hline
\end{tabular}


Table 6 Characterization of the optimized REP-AHAD oral films

\begin{tabular}{|c|c|c|c|c|c|c|c|}
\hline \multirow[t]{2}{*}{$\mathbf{F}$} & \multirow{2}{*}{$\begin{array}{l}\text { Drug content } \\
\text { (\%)* }\end{array}$} & \multirow{2}{*}{$\begin{array}{l}\text { Film thickness } \\
(\mathrm{mm})^{*}\end{array}$} & \multirow{2}{*}{$\begin{array}{l}\text { Folding } \\
\text { endurance }(n) *\end{array}$} & \multirow{2}{*}{$\begin{array}{l}\text { Percentage } \\
\text { elongation (\%)* }\end{array}$} & \multirow{2}{*}{$\begin{array}{l}\text { Moisture } \\
\text { content (\%) }\end{array}$} & \multicolumn{2}{|l|}{$\mathrm{pH}$} \\
\hline & & & & & & Surface & Solution \\
\hline FI & $98.353 \pm 6.23$ & $0.12 \pm 0.023$ & $139 \pm 8.12$ & $15.84 \pm 1.15$ & 3.71 & 7.1 & 6.9 \\
\hline F2 & $97.776 \pm 7.33$ & $0.11 \pm 0.017$ & $142 \pm 9.27$ & $16.23 \pm 2.32$ & 4.02 & 6.9 & 6.8 \\
\hline F3 & $98.118 \pm 4.99$ & $0.11 \pm 0.042$ & $|40 \pm 7.9|$ & $15.9 \mid \pm 1.87$ & 3.97 & 6.9 & 6.7 \\
\hline F4 & $98.218 \pm 5.12$ & $0.12 \pm 0.072$ & $|40 \pm 7.1|$ & $15.77 \pm 0.93$ & 4.12 & 7.2 & 7.1 \\
\hline F5 & $97.924 \pm 7.21$ & $0.13 \pm 0.033$ & $|4| \pm 9.52$ & $15.89 \pm 1.59$ & 3.81 & 7.1 & 7.0 \\
\hline
\end{tabular}

Note: *Data are presented as mean \pm SD.

Abbreviations: $n$, times; REP, repaglinide; AHAD, alginate hexyl amide derivative.

from optimized formulae F1 to F5, respectively, while the percentage drug released from alginate film reached $52.78 \%$ in comparison with only $22.981 \%$ for plain REP within the same period. These results are in accordance with the previously discussed regression polynomial model equations, and the 3D plots showed the significant positive effect for AHAD polymer and disintegrant concentration within the proposed constraint levels on the drug release rate from the prepared oral films. The improvement of drug release from alginate film can be attributed to the drug distribution within the film matrix and glycerin co-solvent effect.

Depending on the previous optimization results, optimized F4 film formula with highest drug release rate and least prediction error was selected for further evaluation.

\section{Solid state characterization studies}

Figure 5 shows the results of solid state characterization of the selected oral film formula (F4). The DSC thermogram of REP shows a sharp single endothermic melting peak at $136.28^{\circ} \mathrm{C}$ in accordance with the literature data, ${ }^{44}$ indicating sample purity. This peak completely disappeared in DSC thermogram of the selected film formula (F4), indicating loss of drug crystallinity and uniform dissolution within the formula matrix. Retaining the SSG melting peak at $296.09^{\circ} \mathrm{C}$ without any additional thermal event changes within the thermogram indicated formula mixture compatibility (Figure 5A). The IR spectrum of REP showed the main characteristic functional group stretching peaks at $3,307.99 \mathrm{~cm}^{-1}$ ( $\mathrm{N}-\mathrm{H}$ amide), $3,200-2,805.56 \mathrm{~cm}^{-1}$ (broad carboxylic O-H), 1,687.88 $\mathrm{cm}^{-1}$ (carboxylic $\mathrm{C}=\mathrm{O}$ ) and $1,636.81 \mathrm{~cm}^{-1}($ amide $\mathrm{C}=\mathrm{O}$ ) that were all retained in the spectrum of oral film formula to eliminate the possibility of any chemical incompatibility between the formula components (Figure 5B).

\section{Surface morphological studies}

Scanning electron micrographs (SEM) of the synthesized AHAD and alginate polymer showed that the chemical medication changed the alginate molecular filamentous shape to be irregular spheres with larger size due to the self-aggregation of the synthesized AHAD due to hydrophobic association between the substituted alkyl groups. ${ }^{42}$ The SEM image of the AHAD oral film shows complete homogeneity of the film

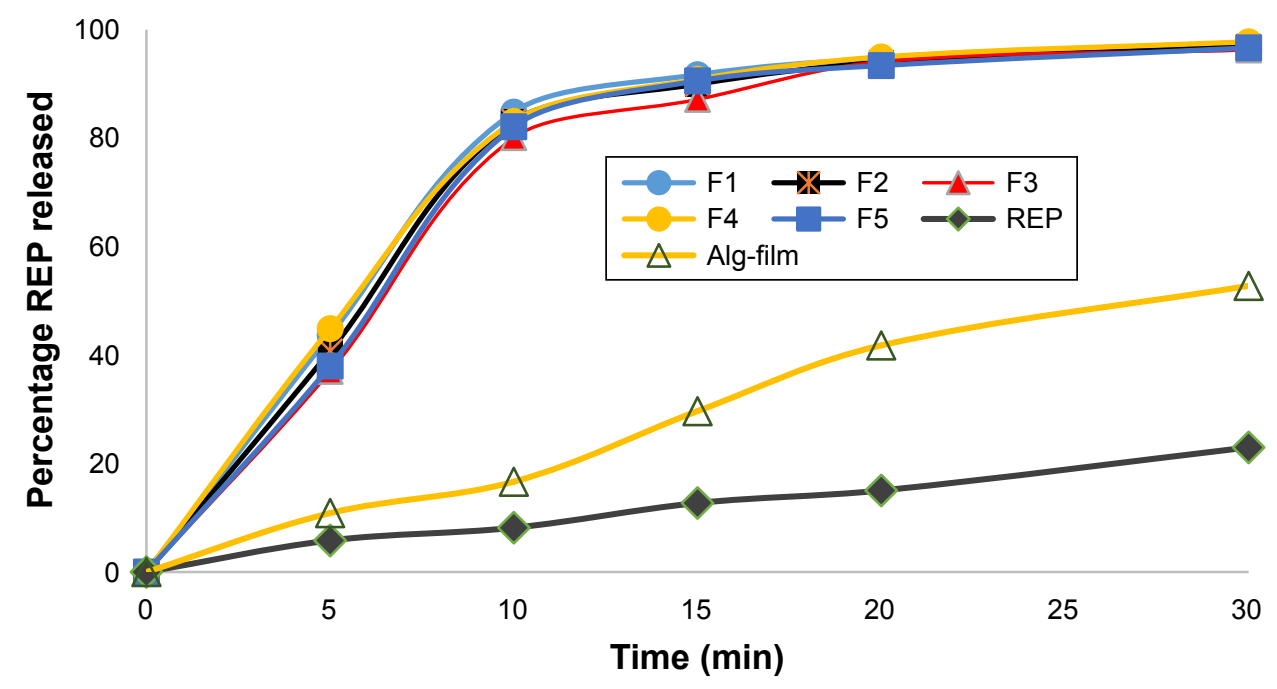

Figure 4 Dissolution profiles of REP from optimized AHAD film formulae in comparison with alginate film and plain drug. Abbreviations: AHAD, alginate hexyl amide derivative; REP, repaglinide; Alg, alginate. 


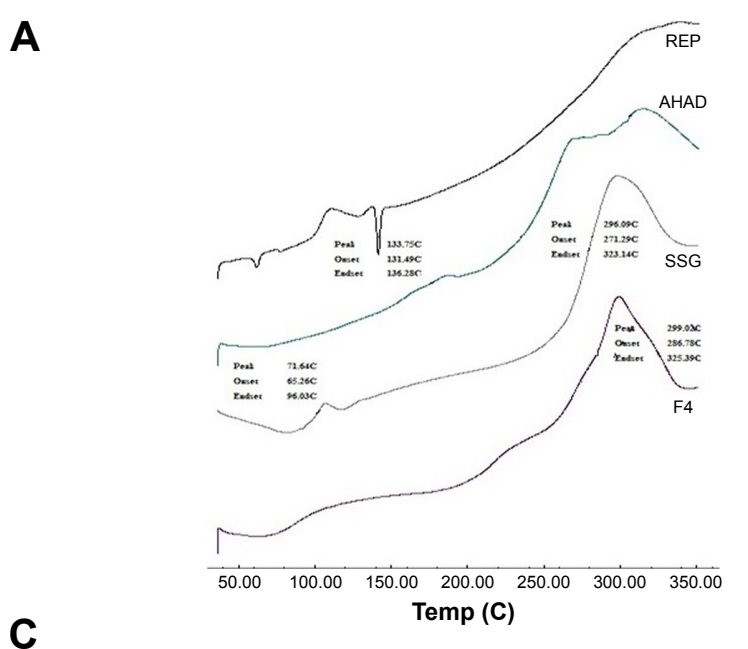

\section{B}
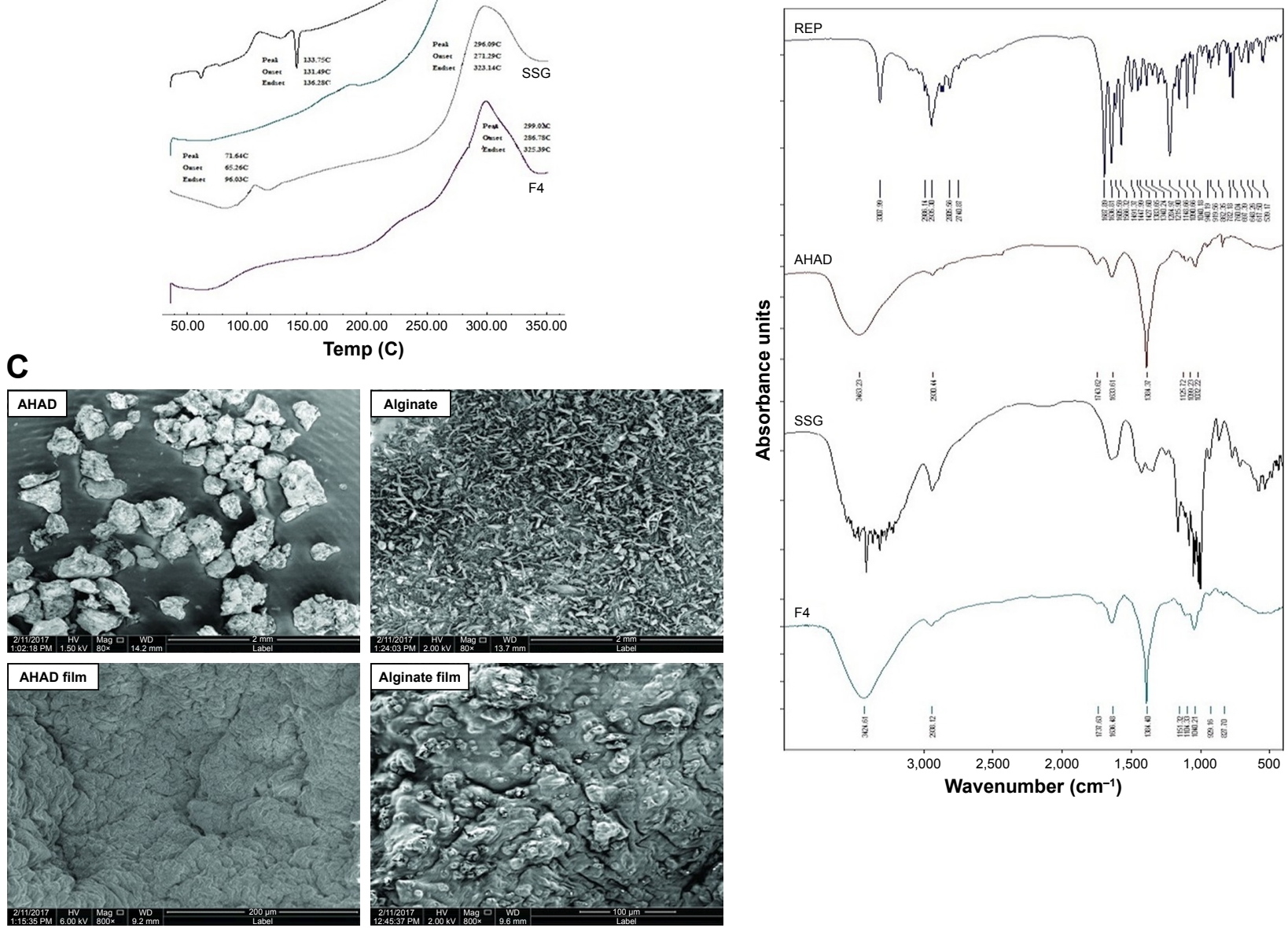

Figure 5 Characterization of optimized film formula (F4) using (A) DSC, (B) FTIR, and (C) scanning electron microscopy.

Abbreviation: DSC, differential scanning calorimetry; FTIR, Fourier-transform infrared spectroscopy.

mixture in comparison with the traditional alginate film that clearly shows precipitated drug particles on the film surface (Figure 5C). This confirms the effect of the chemical modification on the physical properties of alginate and decreasing surface tension with subsequent increase of drug subdivision within the film matrix.

\section{In vivo characterization studies}

To investigate the effect of improvement of REP release rate from the prepared AHAD oral film on its absorption rate and bioavailability, further in vivo studies were applied to the optimized film formula (F4) in comparison with plain drug and conventional alginate oral film.

The non-keratinized nature of rabbit's mucosal membranes with close similarity to human sublingual mucosa suggested it as an animal model for the bioavailability study. ${ }^{45}$ Table 7 summarizes the mean pharmacokinetic parameters of
REP from different forms, and Figure 6 illustrates the mean plasma concentration-time curves.

The calculated pharmacokinetic parameters clearly showed more than threefold increase in AUC value for AHAD film $(296.072 \mu \mathrm{g} . \mathrm{h} / \mathrm{mL})$ in comparison with plain drug $(95.368 \mu \mathrm{g} . \mathrm{h} / \mathrm{mL})$ and about twofold increase when compared

Table 7 The mean pharmacokinetic parameters of REP in different forms after administration to rabbits

\begin{tabular}{l|l|l|l}
\hline $\begin{array}{l}\text { Pharmacokinetic } \\
\text { parameter }\end{array}$ & Plain REP & Alginate film & AHAD film \\
\hline $\mathrm{C}_{\max }(\mu \mathrm{g} / \mathrm{mL})$ & $31.925 \pm \mathrm{I} .62$ & $56.568 \pm 0.598$ & $\mathrm{I} 16.932 \pm \mathrm{I} .563$ \\
$\mathrm{~T}_{\max }(\mathrm{h})$ & $\mathrm{I} \pm 0.143$ & $\mathrm{I} \pm 0.18 \mathrm{I}$ & $0.5 \pm 0.078$ \\
$\mathrm{~K}_{\mathrm{el}}\left(\mathrm{h}^{-1}\right)$ & $0.528 \pm 0.032$ & $0.462 \pm 0.047$ & $0.408 \pm 0.038$ \\
$\mathrm{t}_{1 / 2}(\mathrm{~h})$ & $1.31 \pm 0.117$ & $1.5 \mathrm{I} \pm 0.132$ & $1.69 \pm 0.177$ \\
$\mathrm{AUC}_{0-8}(\mu \mathrm{g} . \mathrm{h} / \mathrm{mL})$ & $93.379 \pm 5.613$ & $160.035 \pm 4.73 \mathrm{I}$ & $285.895 \pm 8.21 \mathrm{I}$ \\
$\mathrm{AUC}_{0-\infty}(\mu \mathrm{gg} . \mathrm{h} / \mathrm{mL})$ & $95.368 \pm 7.216$ & $164.917 \pm 6.548$ & $296.072 \pm 6.947$ \\
\hline
\end{tabular}

Abbreviations: REP, repaglinide; AUC, area under the curve; AHAD, alginate hexyl amide derivative. 


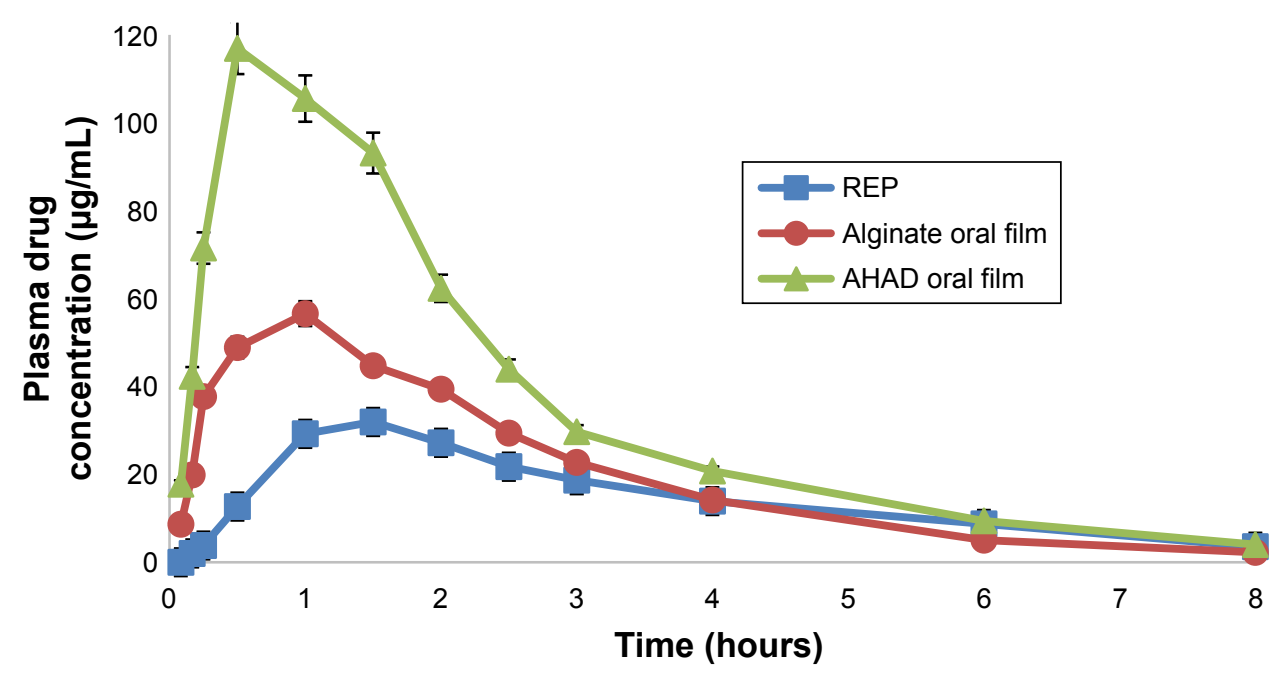

Figure 6 Mean plasma concentration-time curves for optimized film formula (F4) in comparison with conventional alginate film and plain drug in rabbits. Abbreviations: REP, repaglinide; AHAD, alginate hexyl amide derivative.

with alginate film $(164.917 \mu \mathrm{g} . \mathrm{h} / \mathrm{mL})$, also $\mathrm{C}_{\text {max }}$ value increased to reach $116.932 \mu \mathrm{g} / \mathrm{mL}$ in comparison with 31.925 and $56.568 \mu \mathrm{g} / \mathrm{mL}$ for plain drug and alginate film, respectively. REP reached maximum plasma concentration with faster rate from AHAD oral films compared with alginate film and plain drug as indicated by the $50 \%$ reduction of $\mathrm{T}_{\text {max }}$ to be only 30 minutes in comparison with 60 minutes for other forms. The drug bioavailability is usually expressed in terms of extent and rate of drug absorption. Area under plasma concentrationtime curve and maximum drug plasma concentration reflects the amount of drug absorption while the time for maximum plasma concentration is a valuable indicator for adsorption rate. ${ }^{34}$ These results clearly confirm the significant improvement of REP bioavailability from the prepared AHAD oral film formula.

REP is a BCS class II drug of low solubility and high permeability, its absorption is mainly controlled by drug dissolution rate as a limiting step. As previously discussed, ${ }^{30}$ it was proven that the synthesized AHAD polymer material has surfactant properties that cause improvement in the solubility of the loaded drug and release rate with subsequent increase in the amount of drug available for absorption. Dispersion of REP within the alginate matrix also causes decrease of drug crystallinity as indicated by the DSC results (data not shown) explains improvement of drug solubility with subsequent improvement of its rate and extent of absorption from conventional alginate film. Improvement of drug bioavailability is also augmented by the selected administration route that allows drug escaping from liver degradative enzymes (CYP3A4 and CYP2C8) that significantly cause drug metabolism through oxidation and direct conjugation to pharmacologically inactive metabolites.

\section{Statistical analysis of data}

Results of post hoc one-way ANOVA statistical analysis are presented in Table 8, indicating a significant difference

Table 8 One-way ANOVA results for pharmacokinetic data from different forms in rabbits

\begin{tabular}{|c|c|c|c|c|c|c|}
\hline Parameter & Source & Sum of squares & $d f$ & Mean square & $\mathbf{F}$ & Significance \\
\hline \multirow[t]{3}{*}{$\mathrm{C}_{\text {max }}(\mu \mathrm{g} / \mathrm{mL})$} & Between groups & $22,954.319$ & 2 & $11,477.159$ & $6,344.637$ & $<0.001$ \\
\hline & Within groups & 27.134 & 15 & 1.809 & & \\
\hline & Total & $22,98 I .453$ & 17 & & & \\
\hline \multirow{3}{*}{$\mathrm{K}_{\mathrm{el}}\left(\mathrm{h}^{-1}\right)$} & Between groups & 0.042 & 2 & 0.02 & 41.630 & \\
\hline & Within groups & 0.008 & 15 & 0.01 & & \\
\hline & Total & 0.05 & 17 & & & \\
\hline \multirow[t]{3}{*}{$\mathrm{t}_{\mathrm{I} / 2}(\mathrm{~h})$} & Between groups & 0.424 & 2 & 0.212 & 35.080 & \\
\hline & Within groups & 0.091 & 15 & 0.006 & & \\
\hline & Total & 0.514 & 17 & & & \\
\hline \multirow[t]{3}{*}{$\mathrm{AUC}_{0-8}(\mu \mathrm{g} \cdot \mathrm{h} / \mathrm{mL})$} & Between groups & $114,692.838$ & 2 & $57,346.419$ & 927.002 & \\
\hline & Within groups & 927.933 & 15 & 61.862 & & \\
\hline & Total & || $5,620.77 \mid$ & 17 & & & \\
\hline \multirow[t]{3}{*}{$\mathrm{AUC}_{0-\infty}(\mu \mathrm{g} . \mathrm{h} / \mathrm{mL})$} & Between groups & $|24,23| .434$ & 2 & $62,115.717$ & 779.448 & \\
\hline & Within groups & $\mathrm{I}, 195.378$ & 15 & 79.692 & & \\
\hline & Total & $125,426.812$ & 17 & & & \\
\hline
\end{tabular}

Abbreviation: AUC, area under the curve. 
Table 9 Post hoc statistical analysis of the calculated means

\begin{tabular}{|c|c|c|c|c|c|}
\hline \multirow[t]{2}{*}{ Parameter } & \multirow{2}{*}{$\begin{array}{l}\text { Group } \\
\text { AHAD film }\end{array}$} & \multirow[t]{2}{*}{$P$-value } & \multirow[t]{2}{*}{ Mean difference } & \multicolumn{2}{|l|}{ Cl } \\
\hline & & & & Lower & Upper \\
\hline \multirow[t]{2}{*}{$\mathrm{C}_{\max }(\mu g / \mathrm{mL})$} & Plain REP & $<0.001$ & 85.006667 & 82.98968 & 87.02366 \\
\hline & Alginate film & & 60.363333 & 58.34634 & 62.38032 \\
\hline \multirow[t]{2}{*}{$\mathrm{K}_{\mathrm{el}}\left(\mathrm{h}^{-1}\right)$} & Plain REP & & -0.0118 & -0.15172 & -0.08428 \\
\hline & Alginate film & & -0.05 & -0.08372 & -0.01628 \\
\hline \multirow[t]{2}{*}{$\mathrm{t}_{1 / 2}(\mathrm{~h})$} & Plain REP & & 0.37562 & 0.25909 & 0.40215 \\
\hline & Alginate film & & 0.17387 & 0.06184 & 0.29491 \\
\hline \multirow[t]{2}{*}{$\mathrm{AUC}_{0-8}(\mu \mathrm{g} . \mathrm{h} / \mathrm{mL})$} & Plain REP & & 192.516 & 180.7209 & 204.3112 \\
\hline & Alginate film & & 125.8616 & 114.0665 & 137.6567 \\
\hline \multirow[t]{2}{*}{$\mathrm{AUC}_{0-\infty}(\mu \mathrm{g} \cdot \mathrm{h} / \mathrm{mL})$} & Plain REP & & 200.4061 & 187.0186 & 213.7935 \\
\hline & Alginate film & & 130.7956 & 117.4082 & $|44.183|$ \\
\hline
\end{tabular}

Abbreviations: REP, repaglinide; AUC, area under the curve; AHAD, alginate hexyl amide derivative.

between the calculated pharmacokinetic parameters of REP from the different forms with $P$-value of $<0.001$, and post hoc (Tukey mode) statistical analysis results confirmed significance of the recorded variance in drug pharmacokinetic means between AHAD oral films and the other compared drug form. Further result confirmation was applied through studying the $95 \%$ CI (Table 9). Significance of CI for all calculated parameters added more trust to the results as it means that there is $95 \%$ expectation to obtain the same calculated mean within the observed range if the experiment is repeated under the same conditions. Absence of zero value within the calculated CIs with narrow range implies significance, strength, and precision of the results and supports rejection of null hypothesis.

\section{Conclusion}

The optimized AHAD oral film formulae were neutral, homogenous, and rapidly disintegrated with high drug release rate. The AHAD oral film also had satisfactory mechanical properties with high flexibility and elasticity. The drug bioavailability was significantly improved from optimized oral film formula in comparison with plain drug and conventional alginate films. Depending on the previous results, it could be concluded that the synthesized hexyl alginate derivative is an innovative film-forming polymer with unique flexible, amphiphilic properties suitable for the preparation of rapidly disintegrating oral films with improved bioavailability especially for poorly water soluble BCS class II drugs. These findings also confirms that amphiphilic alginate derivatives represent promising tools of expected significant pharmaceutical value due to increased chain flexibility and surfactant properties.

\section{Disclosure}

The author reports no conflicts of interest in this work.

\section{References}

1. Oledzka E, Sobczak M. Polymers in the pharmaceutical applicationsNatural and bioactive initiators and catalysts in the synthesis of biodegradable and bioresorbable polyesters and polycarbonates. In Agbo EC, editor. Innovations in Biotechnology: InTech; 2012. Available from: http://www.intechopen.com/books/innovations-in-biotechnology/ polymers-in-the-pharmaceutical-applicationsnatural-and-bioactiveinitiators-and-catalysts-in-the-sy. Accessed May 16, 2018.

2. Kamaly N, Yameen B, Wu J, Farokhzad OC. Degradable controlledrelease polymers and polymeric nanoparticles: mechanisms of controlling drug release. Chem Rev. 2016;116(4):2602-2663.

3. Kamaly N, Xiao Z, Valencia PM, Radovic-Moreno AF, Farokhzad OC. Targeted polymeric therapeutic nanoparticles: design, development and clinical translation. Chem Soc Rev. 2012;41(7):2971-3010.

4. Farokhzad OC, Jon S, Khademhosseini A, et al. Nanoparticle-aptamer bioconjugates: a new approach for targeting prostate cancer cells. Cancer Res. 2004;64(21):7668-7672.

5. Gu F, Zhang L, Teply BA, et al. Precise engineering of targeted nanoparticles by using self-assembled biointegrated block copolymers. Proc Natl Acad Sci U S A. 2008;105(7):2586-2591.

6. Brem H, Gabikian P. Biodegradable polymer implants to treat brain tumors. J Control Release. 2001;74(1-3):63-67.

7. Ta T, Porter TM. Thermosensitive liposomes for localized delivery and triggered release of chemotherapy. J Control Release. 2013;169(1-2):112-125.

8. Li Y, Xiao K, Zhu W, Deng W, Lam KS. Stimuli-responsive crosslinked micelles for on-demand drug delivery against cancers. Adv Drug Deliv Rev. 2014;66:58-73.

9. Fredenberg S, Wahlgren M, Reslow M, Axelsson A. The mechanisms of drug release in poly(lactic-co-glycolic acid)-based drug delivery systems - a review. Int J Pharm. 2011;415(1-2):34-52.

10. Bat E, Zhang Z, Feijen J, Grijpma DW, Poot AA. Biodegradable elastomers for biomedical applications and regenerative medicine. Regen Med. 2014;9(3):385-398.

11. Nicolas J, Mura S, Brambilla D, Mackiewicz N, Couvreur P. Design, functionalization strategies and biomedical applications of targeted biodegradable/biocompatible polymer-based nanocarriers for drug delivery. Chem Soc Rev. 2013;42(3):1147-1235.

12. Matricardi P, di Meo C, Coviello T, Hennink WE, Alhaique F. Interpenetrating polymer networks polysaccharide hydrogels for drug delivery and tissue engineering. Adv Drug Deliv Rev. 2013;65(9):1172-1187.

13. Wen Y, Oh JK. Recent strategies to develop polysaccharide-based nanomaterials for biomedical applications. Macromol Rapid Commun. 2014;35(21):1819-1832.

14. Goodarzi N, Varshochian R, Kamalinia G, Atyabi F, Dinarvand R. A review of polysaccharide cytotoxic drug conjugates for cancer therapy. Carbohydr Polym. 2013;92(2):1280-1293.

15. Ganguly K, Chaturvedi K, More UA, Nadagouda MN, Aminabhavi TM. Polysaccharide-based micro/nanohydrogels for delivering macromolecular therapeutics. J Control Release. 2014;193:162-173. 
16. Cumpstey I. Chemical modification of polysaccharides. ISRN Org Chem. 2013;2013:1-27.

17. Li S, Xiong Q, Lai X, et al. Molecular modification of polysaccharides and resulting bioactivities. Compr Rev Food Sci Food Saf. 2016;15(2): 237-250.

18. Bowles D. Micro-and Macro-Algae: Utility for Industrial Applications Outputs from the EPOBIO Project. University of York: CNAP; 2007. Available from: http://www.etipbioenergy.eu/images/epobio_aquatic_ report.pdf. Accessed June 6, 2018.

19. Laurienzo P. Marine polysaccharides in pharmaceutical applications: an overview. Mar Drugs. 2010;8(9):2435-2465.

20. George M, Abraham TE. Polyionic hydrocolloids for the intestinal delivery of protein drugs: alginate and chitosan - a review. J Control Release. 2006;114(1):1-14.

21. Silva CM, Ribeiro AJ, Figueiredo M, Ferreira D, Veiga F. Microencapsulation of hemoglobin in chitosan-coated alginate microspheres prepared by emulsification/internal gelation. AAPS J. 2005;7(4):E903-E913.

22. Pawar SN, Edgar KJ. Alginate derivatization: a review of chemistry, properties and applications. Biomaterials. 2012;33(11):3279-3305.

23. Irfan $\mathrm{M}$, Rabel $\mathrm{S}$, Bukhtar Q, et al. Orally disintegrating films: a modern expansion in drug delivery system. Saudi Pharm J. 2016;24(5):537-546.

24. Gavhane YN, Yadav AV. Loss of orally administered drugs in GI tract. Saudi Pharm J. 2012;20(4):331-344.

25. Batchelor HK, Marriott JF. Formulations for children: problems and solutions. Br J Clin Pharmacol. 2015;79(3):405-418.

26. Ali M, Vijendar C, Kumar S, et al. Formulation and evaluation of fast dissolving oral films of diazepam. J Pharmacovigilance 4:210. doi: 10.4172/2329-6887.1000210

27. Bala R, Khanna S, Pawar P. Design optimization and in vitro-in vivo evaluation of orally dissolving strips of clobazam. J Drug Deliv. 2014; 2014:1-15.

28. Landová H, Vetchý D, Gajdziok J, et al. Evaluation of the influence of formulation and process variables on mechanical properties of oral mucoadhesive films using multivariate data analysis. Biomed Res Int. 2014;2014:1-9.

29. Liu M, Cao W, Sun Y, He Z. Preparation, characterization and in vivo evaluation of formulation of repaglinide with hydroxypropyl- $\beta$ cyclodextrin. Int J Pharm. 2014;477(1-2):159-166.

30. Khames A, Abdelazeem AH, Habash M, Taha MO. Preparation and in vitro characterization of glibenclamide-loaded alginate hexyl-amide beads: a novel drug delivery system to improve the dissolution rate. Pharm Dev Technol. 2014;19(7):881-890.

31. Patel A. Mucoadhesive buccal films based on chitosan and carboxymethylated FERONIA Limonia fruit pulp mucilage Interpolymer complex for delivery of opioid analgesics. Asian J Pharm. 2016;10(2):137-143.

32. Patel D, Patel C, Shah P. Formulation and evaluation of bioadhesive buccal drug delivery of repaglinide tablets. Asian J Pharm. 2012;6(3): 171-179.
33. Pimparade MB, Vo A, Maurya AS, et al. Development and evaluation of an oral fast disintegrating anti-allergic film using hot-melt extrusion technology. Eur J Pharm Biopharm. 2017;119:81-90.

34. Khames A. Investigation of the effect of solubility increase at the main absorption site on bioavailability of BCS class II drug (risperidone) using liquisolid technique. Drug Deliv. 2017;24(1):328-338.

35. Sekhar MC. Effect of simvastatin on the pharmacodynamic activity of repaglinide in Rats/Rabbits. Int J Diabet Res. 2012;1(4):52-57.

36. Salman ZD, Maraie NK, Alabbassi MG, Ghareeb MM. In Vitro/In Vivo Evaluation and Bioavailability Study of Amitriptyline Hydrochloride from the Optimized Oral Fast Dissolving Films. UK J Pharm Biosci. 2014;2(6):32-42

37. Megan H, Nowland RL. Guidelines on anesthesia and analgesia in rabbits: Michigan medicine confluence; 2017. Available from: https://wiki. med.umich.edu/display/ULAMGSOP/Guidelines+on+Anesthesia+ and+Analgesia+in+Rabbits. Accessed June 6, 2018.

38. Zhang J, Gao F, Guan X, et al. Determination of repaglinide in human plasma by high-performance liquid chromatography-tandem mass spectrometry. Acta Pharmaceutica Sinica B. 2011;1(1):40-45.

39. Montgomery DC. Design and Analysis of Experiments. 9th ed. Hoboken (NJ): John Wiley \& Sons, Inc; 2017. Available from: https://www. wiley.com/en-us/Design+and+Analysis+of+Experiments $\% 2 \mathrm{C}+9 \mathrm{th}+\mathrm{E}$ dition-p-9781119113478 [online]. Accessed September 12, 2018.

40. Kaur P, Garg T, Rath G, Murthy RSR, Goyal AK. Development, optimization and evaluation of surfactant-based pulmonary nanolipid carrier system of paclitaxel for the management of drug resistance lung cancer using Box-Behnken design. Drug Deliv. 2016;23(6): 1912-1925.

41. Hao J, Fang X, Zhou Y, et al. Development and optimization of solid lipid nanoparticle formulation for ophthalmic delivery of chloramphenicol using a Box-Behnken design. Int J Nanomedicine. 2011;6: 683-693.

42. Chen X, Yan H, Sun W, et al. Synthesis of amphiphilic alginate derivatives and electrospinning blend nanofibers: a novel hydrophobic drug carrier. Polymer Bulletin. 2015;72(12):3097-3117.

43. Liew KB, Tan YTF, Peh K-K. Effect of polymer, plasticizer and filler on orally disintegrating film. Drug Dev Ind Pharm. 2014;40(1):110-119.

44. Shams T, Sayeed MSB, Kadir MF, et al. Thermal, infrared characterization and in vitro evaluation of repaglinide solid dispersion. Der Pharmacia Lettre. 2011;3(6):142-150.

45. Odou P, Barthélémy C, Chatelier D, et al. Pharmacokinetics of midazolam: comparison of sublingual and intravenous routes in rabbit. Eur J Drug Metab Pharmacokinet. 1999;24(1):1-7.
Drug Design, Development and Therapy

\section{Publish your work in this journal}

Drug Design, Development and Therapy is an international, peerreviewed open-access journal that spans the spectrum of drug design and development through to clinical applications. Clinical outcomes, patient safety, and programs for the development and effective, safe, and sustained use of medicines are the features of the journal, which

\section{Dovepress}

has also been accepted for indexing on PubMed Central. The manuscript management system is completely online and includes a very quick and fair peer-review system, which is all easy to use. Visit http://www.dovepress.com/testimonials.php to read real quotes from published authors. 